\title{
Uncertainty in risk issues for carbon capture and geological storage: findings from a structured expert elicitation
}

\author{
Patricia Larkin* \\ McLaughlin Centre for Population Health Risk Assessment, \\ University of Ottawa, \\ Room 216A, 600 Peter Morand Crescent, \\ Ottawa, K1G 5Z3, Ontario, Canada \\ Email: plarkin@xplornet.com \\ *Corresponding author
}

\section{Robert Gracie}

Department of Civil and Environmental Engineering, University of Waterloo, 200 University Avenue West, Room E2-2321, Waterloo, N2L 3G1, Ontario, Canada Email: rgracie@uwaterloo.ca

\section{Ali Shafiei}

Department of Petroleum Engineering, School of Mining and Geosciences, Nazarbayev University, 53 Kabanbay Batyr Ave., Nur-Sultan, 010000, Republic of Kazakhstan

Email: ali.shafiei@nu.edu.kz

\section{Maurice Dusseault}

Department of Earth and Environmental Sciences, University of Waterloo, 200 University Avenue West, EIT-2043,

Waterloo, N2L 3G1, Ontario, Canada

Email: mauriced@uwaterloo.ca

\section{Mirhamed Sarkarfarshi}

CIBC Global Markets, Toronto, Ontario, Canada Email: Sarkarfarshi@gmail.com 


\title{
Willy Aspinall
}

School of Earth Sciences,

University of Bristol,

Beacon House, Queens Road, Bristol, BS8 1QU, UK

Email: willy.aspinall@bristol.ac.uk

\section{Daniel Krewski}

McLaughlin Centre for Population Health Risk Assessment, University of Ottawa, Room 216A, 600 Peter Morand Crescent, Ottawa, K1G 5Z3, Ontario, Canada

Email: dkrewski@uottawa.ca

\begin{abstract}
Carbon capture and geological storage (CCS) is identified within the portfolio of mitigation options for climate change. Each value chain activity of large scale integrated projects (capture, transport, injection and storage) includes uncertainties and hence potential risks with respect to both environmental and human health protection. With a focus on injection and storage, a structured elicitation of international experts provides quantified judgements and uncertainties and understanding of relative risk of CCS activities. In the 0-50 year, 51-499 year and $>500$ year time periods, the expert panel suggested an almost equal likelihood of storage leakage occurring, with a marked decrease from minor to major to catastrophic leakage (approximately $>1$ in $30 ; 1$ in $103 ; 1$ in 104 , respectively); for the same time periods, the judgement of likelihood for major leakage that would result in measurable negative effects on human health or the environment was the same (approximately 1 in 103). Insights could stimulate further scientific deliberations about the reliable and effective deployment of this complex and interdisciplinary technological process. A companion paper discusses complementary findings for issues in CCS risk management.
\end{abstract}

Keywords: carbon capture and storage; expert elicitation; risk assessment; uncertainty; public health; environmental protection; injection; geological sequestration.

Reference to this paper should be made as follows: Larkin, P., Gracie, R., Shafiei, A., Dusseault, M., Sarkarfarshi, M., Aspinall, W. and Krewski, D. (2019) 'Uncertainty in risk issues for carbon capture and geological storage: findings from a structured expert elicitation', Int. J. Risk Assessment and Management, Vol. 22, Nos. 3/4, pp.429-463.

Biographical notes: Patricia Larkin is a Post-Doctoral Fellow at the University of Ottawa. Her field of research, population health, considers structural and intermediary determinants of health and their interactions, with a goal to protect or improve human health. With a focus on applied risk management, she is undertaking research, writing and project management at the McLaughlin Centre for Population Health Risk Assessment and the Institute for Science Society and Policy. She is an active member of the Society for Risk Analysis. She holds her Master's in Geography and Graduate Diploma in Population Health Risk Assessment and Management. 
Robert Gracie is an Associate Professor at the Department of Civil and Environmental Engineering, at the University of Waterloo (UW). His PhD from Northwestern University focused on the Simulation of Deformation and Fracture of Solids in 2009, prior to which he analysed interactions between ice, soil and offshore pipelines at Natural Resources Canada. At UW, he teaches courses in solid mechanics, finite element analysis and nonlinear computational mechanics and carries out research in the development of numerical methods to simulate the deformation and fracture of solids and the flow of fluids. He is known for his work on the extended finite element method (XFEM), which was developed specifically to simulate fracture, dislocations and multiphase flow. He has 27 journal articles on related topics. His current research projects include developing new simulation technologies for multiphase-phase flow during carbon sequestration, hydraulic fracturing of rock masses and microscale plasticity.

Ali Shafiei is an Assistant Professor of Petroleum Engineering with the Department of Petroleum Engineering at Nazarbayev University (NU) in Kazakhstan. He is a founding team member of the petroleum engineering program in NU and leads the BSc program in Petroleum Engineering. He completed his $\mathrm{PhD}$ in 2013 in Heavy Oil Recovery and Reservoir Geomechanics from the University of Waterloo in Canada. At NU, he teaches petrophysics, well logging, formation evaluation, petroleum geology, reservoir geomechanics, and heavy oil recovery. His current research projects include low salinity water flooding and asphaltene precipitation in petroleum reservoirs. As of today, his professional and academic experience has resulted in more than 40 refereed journal papers, vetted conference proceedings, chapters in books and monographs. He is an active member of the SPE, EAGE, and AAPG. He is also a Faculty Advisor of the NU SPE Student Chapter.

Maurice Dusseault teaches geological engineering and does research in deep underground engineering issues including hydraulic fracturing, energy storage, geothermal energy, mining, carbon sequestration, deep solids and liquids waste disposal through injection and wellbore integrity. He holds over 80 international patents and has about 525 full-text papers published in journals and conferences. He is a well-known educator and advisor and in the last few years has served as advisor to five different Canadian provinces $(\mathrm{AB}, \mathrm{QC}, \mathrm{NB}$, $\mathrm{NS}$, and NL) on matters relating to energy development, hydraulic fracturing, energy geostorage, wellbore integrity, technology and innovation.

Mirhamed (Araz) Sarkarfarshi completed his PhD at the Department of Civil and Environmental Engineering, University of Waterloo. He currently works as a Senior Quantitative Analyst, Capital Markets Risk Management, CIBC Toronto, Ontario, Canada.

Willy Aspinall is a consulting Chartered Scientist and Chartered Geologist and Cabot Professor in Natural Hazards and Risk Science at the University of Bristol UK. His main interests are in risk assessment, volcanology and seismology and the formalised use of expert judgement in decision-making for low probability, high consequence events in circumstances of scientific uncertainty. He specialises in facilitating expert elicitations in medical, climate, Earth science and other science-based fields. He was awarded the 2012 William Smith Medal of the Geological Society of London for excellence in contributions to applied geoscience and was co-recipient with Bristol University colleagues of the 2014 Lloyd's of London Science of Risk Prize for Natural Hazards and the 2015 The Queen's Anniversary Prize for Higher and Further Education. 
Daniel Krewski is a Professor of Epidemiology and Community Medicine at the University of Ottawa, where he also serves as a Scientific Director of the McLaughlin Centre for Population Health Risk Assessment. His research interests include epidemiology, biostatistics, health risk assessment and risk management. He is a Fellow of the Society for Risk Analysis, the American Statistical Association and a national affiliate of the US National Academy of Sciences. He holds the Natural Sciences and Engineering Research Council of Canada Chair in Risk Science at the University of Ottawa.

\section{Introduction}

Carbon dioxide $\left(\mathrm{CO}_{2}\right)$ is a greenhouse gas $(\mathrm{GHG})$ that has been identified as a significant driver of climate change, with $65 \%$ of GHG emissions attributed to $\mathrm{CO}_{2}$ in 2010 (IPCC, 2014). From an estimated $27 \mathrm{GtCO}_{2}$ eq/year (Giga tonnes of $\mathrm{CO}_{2}$ equivalent per year) emissions in 1970, GHGs are trending towards or may exceed $55 \mathrm{GtCO}_{2} \mathrm{eq} / \mathrm{year}$ through 2030, even with implementation of the full range of unconditional and conditional components of intended nationally determined climate change mitigation actions (Benveniste et al., 2018; United Nations Framework Convention on Climate Change, 2016). This amount of emissions has been modelled to result in an atmospheric concentration of $580-720 \mathrm{ppm} \mathrm{CO}_{2} \mathrm{eq}$, higher than the $450 \mathrm{ppm}$ that could limit average global temperature increase to $+2.0 \mathrm{oC}$ (2DS) by 2100 , the international Paris Agreement target (United Nations Framework Convention on Climate Change, 2015).

In an effort to cut $\mathrm{CO}_{2}$ emissions from point source fossil fuel and industrial process sites - such as coal and natural gas electricity generation facilities and cement, steel, fertiliser and oil upgrader facilities - carbon capture and geological storage (CCS) technology has been included within the portfolio of mitigation options for climate change (IEA, 2013; IPCC, 2005, 2014). Up to 3,000 saline aquifer sequestration projects could contribute $12 \%-14 \%$ cumulative $\mathrm{CO}_{2}$ emission reductions worldwide through 2050 (GCCSI, 2017; IEA, 2016).

Large scale integrated CCS projects include four value chain activities: $\mathrm{CO}_{2}$ capture and compression to supercritical fluid phase, transport by pipeline, underground injection and permanent storage in deep geological formations. Potential environmental and human health hazards have been identified for each of these activities, with greater understanding of risk assessment for capture (an industrial process) and transport, compared with less but growing experience for $\mathrm{CO}_{2}$ injection and saline storage activities (Koornneef et al., 2012; Pawar et al., 2015).

The objectives of the study were to gauge risk and uncertainty associated with potential hazards in large scale sequestration projects. The expert elicitation was focused on performance and containment hazards in injection and storage. The elicitation also considered issues in CCS risk management, with a focus on low probability high impact events, findings for which are detailed in Larkin et al. (2019a).

The following sections first explain the terminology and approach used in this analysis, including the CCS technology, an overview of technical, environmental and health issues associated with the technology and previous findings from expert elicitation. 


\subsection{CCS technological process}

Pre-combustion, post-combustion and oxyfuel combustion-based carbon dioxide capture technologies are currently applied or proposed for power generation and industrial facilities. Capture activities also include compression to a supercritical fluid phase (Kunze and Spliethoff, 2012). For the purposes of the present discussion, transport is limited to pipelines. Deep well injection occurs at wells located within the storage complex.

Deep saline aquifers are considered the most widely available candidates for geological $\mathrm{CO}_{2}$ sequestration, with approximately 800 major sedimentary basins existing worldwide (Bachu, 2003). Given the need for thousands of sequestration projects in order for CCS to contribute its full potential to climate change mitigation, this storage formation was the focus of the elicitation.

Elicitation questions related to carbon capture utilisation and storage (CCUS) in $\mathrm{CO}_{2}$ enhanced oil recovery (EOR) or enhanced coal bed methane (CBM) operations (the latter not a notable option either in terms of storage capacity or availability) were included in a limited way. In EOR operations usually there is a significant amount of data available from previous injection and production activities to reduce the uncertainty associated with the risks of storage. These projects are described and promoted as proof of concept, demonstrating that $\mathrm{CO}_{2}$ remains stored underground over an extended period of time. The less common $\mathrm{CBM}$ field pilot projects inject $\mathrm{CO}_{2}$ into coal seams where most remains permanently stored (GCCSI, 2018; MIT, 2018).

\subsection{Technical, environmental and human health hazards}

Technical hazards in CCS relate to site performance and containment, both of which have the potential to affect the successful operation of the project. As described by Pawar et al. (2015) and Sarkarfarshi et al. (2019), performance issues include insufficient injectivity or storage capacity during site assessment and injection phase activities. Substantial research has been devoted to identifying and verifying the main processes for each of these risk categories. Reviews were completed by, for example, Bachu (2015) regarding storage efficiency, and Birkholzer et al. (2015) and Celia et al. (2015) regarding migration, trapping and containment in deep saline aquifers.

With respect to containment, $\mathrm{CO}_{2}$ and brine hazards may manifest during the injection and post-injection (storage) period, possibly creating risks for the environment and human health. Wilson et al. (2003) created a taxonomy of risks of geologic sequestration that included, at the local level, $\mathrm{CO}_{2}$ in the atmosphere or shallow subsurface (with results such as human and animal suffocation, effects on plants, roots, insects, burrowing animals); $\mathrm{CO}_{2}$ dissolved in subsurface fluids (causing mobilisation of metals, potable water contamination, interference with deep-subsurface ecosystems); displacement (such as ground heave, induced seismicity, water contamination by brines, damage to hydrocarbon or mineral resources); and release of stored $\mathrm{CO}_{2}$ to the atmosphere, with global ramifications. Environmental hazards were also detailed by Koornneef et al. (2012) and Pawar et al. (2015), including air, soil and groundwater contamination by $\mathrm{CO}_{2}$, brine or process contaminants affecting the natural environment. Additionally, the biosphere hazards assessed by Bowden et al. (2013a) further included 
effects on wildlife, prairie, recreation and industry assets related to air, soil and water contamination. Jones et al. (2015) discussed improved understanding of potential environmental impacts of $\mathrm{CO}_{2}$ leakage on drinking water resources and near surface ecosystems for both onshore and offshore CCS projects.

Potential human health hazards include occupational or public morbidity and mortality caused by inhalation of concentrated $\mathrm{CO}_{2}$ that could return to the surface (Roberts et al., 2011) and induced seismicity effects on built infrastructure (White and Foxall, 2016). As well, potential re-release of stored $\mathrm{CO}_{2}$ could contribute GHG emissions back into the atmosphere with attendant health effects of an exacerbated climate change scenario. From a population health perspective, the natural and built environment are included as determinants of human health, defined as the circumstances in which populations are born, grow up, live, work and age (Commission on Social Determinants of Health, 2008). $\mathrm{CO}_{2}$ or brine effects on drinking water, soil and air contamination, as well as wildlife and habitat, may therefore also be considered health hazards.

\subsection{Structured expert elicitation}

CCS in saline aquifers is a new technology, with just two large scale projects operating over the past ten years and two more operating since 2015 (GCCSI, 2018; MIT, 2018). As such, CCS at a large scale is a good candidate for a structured expert elicitation, an approach that has been shown to be of value where there is limited information and experience, large uncertainties and risks are theoretically very low (Aspinall, 2010). Previously, structured expert elicitation has been applied to wide ranging issues of collective importance (Colson and Cooke, 2017; Cooke and Goossens, 2008), including water pollution, the aerospace sector, volcanoes; nuclear applications (Siegel et al., 2018); health risk related to chronic wasting disease (Oraby et al., 2016); prion disease (Tyshenko et al., 2012; Tyshenko et al., 2011) and global foodborne disease burden (Hald et al., 2016).

Gerstenberger and Christophersen (2016) combined a structured expert elicitation with Bayesian Belief Networks analysis in a research project to demonstrate the use of these methods in assessing the probability that the $\mathrm{CO}_{2} \mathrm{CRC}$ Otway Stage $2 \mathrm{C}$ experiment (Australia) would meet its goals of detecting and stabilising a $\mathrm{CO}_{2}$ plume using a $4 \mathrm{D}$ seismic monitoring survey. Their findings focused on the implications of the impacts of the methods more so than the implications for the project, suggesting that the Cooke Classical Model for structured expert elicitation provides a more defensible and useful procedure compared with informal methods, particularly because of the "transparent and unbiased weighting scheme and the influential role it plays in encouraging experts to be open minded during the elicitation by its emphasis on uncertainty in one's own knowledge" (Gerstenberger and Christophersen, 2016, p.328).

Using non-structured elicitation, geological aspects of containment risk for the Otway project were also quantified (Watson, 2014). The normalised risk quotient for the likelihood of more than ten leakage events was lower than the target risk quotient in all cases. Other non-structured expert elicitations have been used in CCS and CCUS project risk assessments (Pawar et al., 2015), to discern the evolving perceptions of risk for two model CCS projects in Scotland (Polson et al., 2012) and selected geosphere and biosphere risks of the IEAGHG Weyburn-Midale $\mathrm{CO}_{2}$ Monitoring Project (Bowden et al., 2013a, 2013b) (see also Larkin et al., 2019b). In Polson et al. (2012), experts first 
indicated mostly low risk perception for features, events and processes (FEPs) in their risk register for two model saline aquifer reservoirs and new information reduced uncertainty further during the course of the project. However, experts also displayed a change in risk perception for some issues in the absence of new information, with authors suggesting a need to understand the factors that may have contributed to this difference. For Weyburn-Midale, risk workshops were used to develop a risk register and a quantitative assessment of the consequence and likelihood of geosphere containment risks (Bowden et al., 2013b). The process demonstrated that it is likely that approximately $30 \mathrm{Mt} \mathrm{CO}_{2}$ could be expected to be stored safely in the EOR project for an extended period of time. Results were linked with semi-quantitative risk assessment for the biosphere where, among several findings, the project posed an acceptable level of risk to public safety; well pathways pose the greatest biosphere risk; and public amenity assets - sensory perception, agriculture and property/infrastructure - are most at risk due to movement of $\mathrm{CO}_{2}$ into channel aquifers (Bowden et al., 2013a, p.S307).

\section{Methods}

A panel of twelve international experts, recognised as authorities in the field of CCS, was convened over two consecutive part-days in March 2015 to elicit understanding and beliefs about risks and uncertainty, with emphasis on injection and storage and risk management of low probability high impact (LPHI) events. Five members work in academia and seven in government research agencies. They brought expertise in hydrology and fluid mechanics, geomechanics, geophysics, well integrity, simulation and mathematical modelling, risk assessment and monitoring. Prior to the elicitation, a draft elicitation instrument was reviewed and tested by additional experts in CCS injection and storage, following which some modifications were made and one question was removed. The facilitated elicitation then took place using video conferencing facilities hosted by the University of Ottawa. Panel members were located in Canada, the USA, Europe, Australia and Saudi Arabia. One participant withdrew voluntarily after the first day citing insufficient familiarity with the subject matter. The responses provided by that participant are excluded from the analysis.

Experts understood the elicitation was concerned with a generic risk scenario and did not constitute a risk assessment or management exercise for a specific project scenario. Before beginning the elicitation, a crucial step was to establish that participants had a common understanding of terms and conditions embedded in the elicitation instrument, arriving at the following agreed terms:

- Risk referred to probability and consequence of an adverse effect combined.

- The term ' $\mathrm{CO}_{2}$ leakage' represented both leakage and seepage scenarios and questions did not differentiate between point source leakage or diffuse leakage over a large area.

- CCS leakage failure scenarios included:

a minor leakage (light and slow, escaping repository)

b major leakage (requiring intervention to mitigate effects)

c catastrophic leakage (with significant infrastructure damage or evacuation). 
- The amount of leakage could be considered in terms of:

a the percentage of the mass injection rate of $\mathrm{CO}_{2}$

b the percentage of total injected $\mathrm{CO}_{2}$ mass

c the total mass of leaked $\mathrm{CO}_{2}$ per year.

- Injection concerned well operations, including the facility, wellbore and near wellbore zone.

- Storage included conditions away from the wellbore that may affect the integrity of repository.

- CCS projects were expected to be developed in low to medium population density areas, remote from major urban centres.

- The elicitation did not attempt to assess judgements as to what constitutes an 'acceptable' level of risk.

Questions of clarification and interpretation were permitted throughout the process; some definitions and contextual understandings were refined during the course of the elicitation. During the virtual plenary session, experts completed each question individually using pre-formatted spreadsheet response tables, which were submitted by the experts to us at completion. Throughout, experts were also given the opportunity to record their thoughts and reasoning and to comment on the elicitation process.

Three question formats were used to elicit responses to questions on CCS risk assessment issues.

1 Paired comparisons: Experts completed the upper triangular part of preference matrices to compare relative risks of capture, transport, injection and storage; longterm risks of storage options; distinct causes of local health and environmental hazards in low/moderately populated areas; and mineral reactivities. Pairwise preference semi-quantitative ranking was obtained by probabilistic inversion of the importance ordering choices using the Unibalance software (Macutkiewicz and Cooke, 2006; Tyshenko et al., 2011). Experts' internal consistency was evaluated in assessing pairwise preferences.

2 Numerical uncertainty distributions: According to the classical model of Cooke (Colson and Cooke, 2018; Cooke, 1991, 2009, 2013) experts first completed a series of (18) calibration questions on technical CCS issues in site performance and containment; these were variables with values known from the literature, which experts would not be expected to know precisely, but should be able to capture within credible uncertainty distributions ( $90 \%$ range). This calibration exercise enabled distinct performance weights to be given to individual experts based on their accuracy and ability to judge uncertainties (Aspinall, 2008; Aspinall and Cooke, 2013; Colson and Cooke, 2018; Cooke, 1991). This method remains the only technique currently available that has the attribute of genuine empirical control on the resulting individual performance scores. For a detailed description, see Cooke (1991), Cooke and Goossens (2008), Tyshenko et al. (2011) and Colson and Cooke (2018). For target items, experts' elicited quantiles were aggregated with these weights to form a new distribution: the performance weight (PW) solution, expressing the group view on the item median value and uncertainty distribution. 
This is a mathematically valid and auditable procedure for arriving at a rational consensus on the group view (Cooke, 1991). The calibration questions focused on saline aquifer sequestration site performance and containment. Two calibration questions that related specifically to capture and transport were discarded from the performance weight calibration, because responses did not contribute information to help discriminate between experts.

Experts responded to numerical uncertainty distribution target questions with a central value (median) best judgement (50th percentile) and the $90 \%$ credible range (lower limit 5 th percentile and upper limit 95 th percentile). Target questions considered the likelihood of leakage in three time periods, the likelihood that major leakage that would result in significant effects on the local environment or human health, storage capacity and injectivity and seismicity. Responses to calibration and target questions using this format were processed using the EXCALIBUR software package.

3 Likert scale rating: A 5-level Likert scale was used to elicit expert opinion on the likelihood and severity of 29 hazards within four hazard groups: well leakage, injection, intrinsic storage hazards and induced storage hazards. The same scale was used by Polson et al. (2012) (Table 1). The mean expert score was calculated, along with its standard error in order to provide a measure of uncertainty in expert opinion.

Table 1 Likelihood and severity descriptors for Likert scale rating of hazards

\begin{tabular}{|c|c|c|}
\hline Level & $\begin{array}{c}\text { Likelihood-if there were } 100 \text { similar } \\
\text { projects, frequency of this hazard } \\
\text { element would occur }\end{array}$ & Severity - change in state \\
\hline 1 & Improbable - probably not at all, never & Light - no modification to initial state \\
\hline 2 & $\begin{array}{l}\text { Unlikely - fewer than three times } \\
\text { among the } 100 \text { projects }\end{array}$ & $\begin{array}{c}\text { Serious - modification to initial state } \\
\text { within acceptable limits }\end{array}$ \\
\hline 3 & $\begin{array}{c}\text { Possible }-5-10 \text { times among the } 100 \\
\text { projects }\end{array}$ & $\begin{array}{l}\text { Major - modification to initial state above } \\
\text { acceptable limits but without damage }\end{array}$ \\
\hline 4 & $\begin{array}{l}\text { Likely - in around half of the } 100 \\
\text { projects }\end{array}$ & $\begin{array}{c}\text { Catastrophic - modification to initial state } \\
\text { above acceptable limit with repairable } \\
\text { damage }\end{array}$ \\
\hline 5 & $\begin{array}{c}\text { Probable - in most or nearly all of the } \\
\text { projects }\end{array}$ & $\begin{array}{l}\text { Multi Catastrophic - considerable } \\
\text { modifications to initial state which is not } \\
\text { catastrophic repairable with existing } \\
\text { technologies }\end{array}$ \\
\hline
\end{tabular}

Source: Adapted from Polson et al. (2012)

A third facilitated video conference provided the expert panel with an opportunity to review preliminary findings. Experts agreed that several questions required further clarification. An explanatory document, including a rationale for re-elicitation and formatted response tables, was then distributed electronically and experts submitted responses to these final elicitation questions on an individual basis. These questions reconsidered the likelihood of storage leakage scenarios, a regulated threshold for leakage and safe storage lifetimes. A new question considered the likelihood of a measurable negative environmental impact or adverse public health impact, given five levels of hazard severity. 


\section{Results}

Performance weights based on calibration question responses were not applied to paired comparison and Likert scale responses. Target question response detail is provided in the supplementary material.

\subsection{Pairwise preference semi-quantitative ranking scores}

Findings from the pairwise comparisons (PCs) of relative risks of different components of CCS are presented graphically in Figures 1-4, with tabulated results provided in the supplementary material. Ellipses depict approximate 95\% confidence areas for factor ranking scores. For cases with alternative scenarios or options, horizontally extended ellipses indicate greater variance in ranking scores for the option on the $\mathrm{x}$-axis, relative to rankings for the $\mathrm{y}$-axis option; vertically extended ellipses indicate greater variance vice versa. In terms of differentiation between different risks, off-diagonal markers indicate that the rank scores differ for the two alternative risk sources and rank scores clustering near 0.5 indicate the group's responses do not provide evidence to differentiate between risks. When this happens, the corresponding coefficients of agreement or concordance are very low, indicating an absence of any systematic trait in the experts' choices (supplementary material).

PC1: In order to rank the relative risk of four chain activities of integrated carbon capture and storage projects (capture, transport, injection and storage), we need you to indicate which you consider to present the greater risk. Technical (Q1), environmental (Q2) and health risks (Q3) are considered separately.

Figure 1 Pairwise preference matrix of relative risk for capture, transport, injection and storage,

(a) environmental compared with technical risk (b) health compared with technical risk

(c) environmental compared with health risk (see online version for colours)

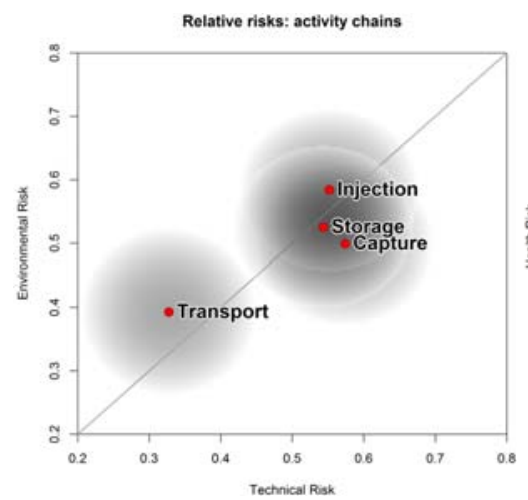

(a)

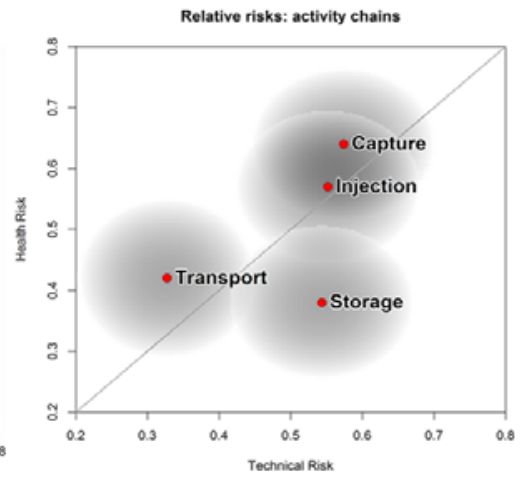

(b) 
Figure 1 Pairwise preference matrix of relative risk for capture, transport, injection and storage, (a) environmental compared with technical risk (b) health compared with technical risk (c) environmental compared with health risk (continued) (see online version for colours)

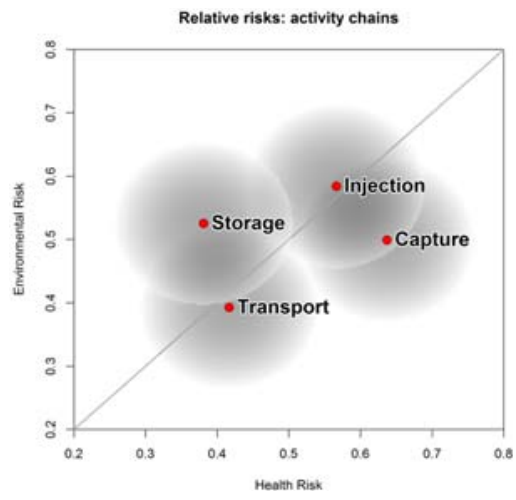

(c)

Figure 2 Relative long-term risk ranking of three storage options (see online version for colours)

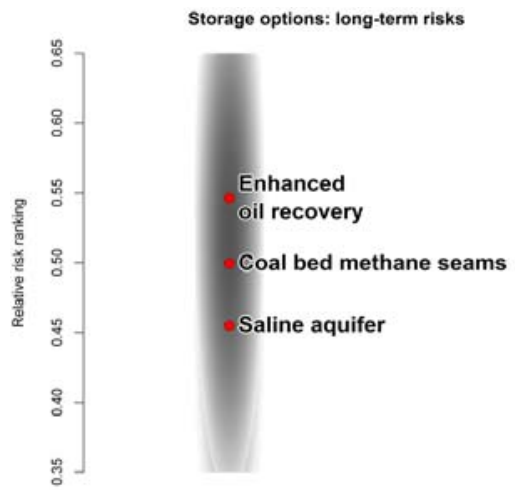

In all three cases (technical, environmental, health), rank scores in general did not separate decisively or systematically. However, in the case of technical risk and environmental risk [Figure 1(a)], transport is ranked well below the other three activities (capture, injection and storage) in the CCS value chain. In the case of health risk and technical risk [Figure 1(b)], storage and transport both rank below capture and injection, with the technical risk of storage ranking higher than health risk. In comparing environmental risk with health risk [Figure 1(c)], experts' rank scores were greater for injection than transport, but did not differ in each case (on diagonal). Capture was judged to present a potentially greater health risk and storage a greater environmental risk. 
$P C 2$ : In order to rank the overall relative risk of the three main types of storage options (saline aquifer; coal bed methane seams; enhanced oil recovery), we need you to indicate which you consider to present the greater risk over the long term ( $>100$ years)?

Saline aquifers, coal bed methane seams and $\mathrm{CO}_{2}$ EOR were compared. The long-term risk was not differentiated in the pairwise preference responses (Figure 2). Note the very narrow scaling for rank scores and the uncertainties in rank score values (as represented by the overlapping vertical ellipses) (see also supplementary material). This indicates experts' did not rank one storage option as being of greater long term risk than another.

PC3: In order to rank the relative risks of distinct causes of local health and environmental hazards in a low to moderately populated area, we need you to indicate which you consider to present the greater risk.

- Brine, $\mathrm{HCO}_{3}$, or elevated gas-phase $\mathrm{CO}_{2}$ migration into the shallow subsurface and near-surface environment.

- A seismic event of magnitude $\mathrm{M}>5$ on the Richter scale.

- Explosive re-release of $\mathrm{CO}_{2}$ to the surface.

- Cap rock integrity loss due to hydraulic fracturing caused by CCS project.

Responses indicate that experts ranked 'hydraulic fracturing caprock failure' as a lower potential hazard compared with 'brine/gas migration in the subsurface/near surface environment', 'explosive $\mathrm{CO}_{2}$ release to the surface' and 'seismic event $>$ M5' (Figure 3).

Figure 3 Relative risk of distinct causes of local health or environmental hazards in a low-moderate populated area (see online version for colours)

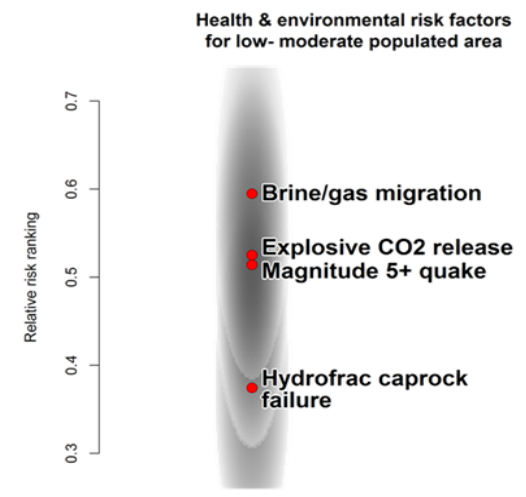

PC4: [In the tables], we need you to indicate the relative reactivity of five naturally occurring minerals with $\mathrm{CO}_{2}$ in the pure supercritical state and $\mathrm{CO}_{2}$ in the dissolved state.

There is good evidence that the group held coherent and self-consistent views for these choices. As shown in Figure 4, the minerals all plot close to the diagonal in rank order, with clear separations between most. The findings reflect values that are computable in 
PHREEQC (Parkhurst and Appelo, 2013), one of two computer simulation models most commonly applied to interpret groundwater changes at injection sites (Jones et al., 2015). This lends confidence that this question type provides legitimate findings for judgements of relative risk for less well-known factors.

Figure 4 Pairwise preference matrix of relative reactivity of five naturally occurring minerals with $\mathrm{CO}_{2}$ in pure supercritical and dissolved state (see online version for colours)

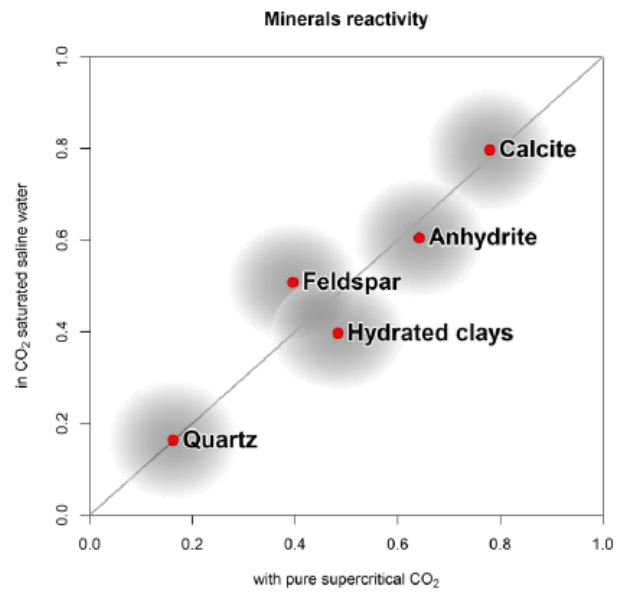

\subsection{Numerical uncertainty distributions}

The median performance-weighted responses and $90 \%$ credible intervals for target questions are reported in numerical form (Table 2). A range graph plot, with individual expert responses, performance-weighted responses and equal-weighted responses (Figure 5); and a composite plot of comparative piece-wise uncertainty distributions (Figure 6) provide examples of the figures that are included for each question in the supplementary material. An $\mathrm{R}$ suffix in target question numbering indicates the question was re-elicited.

In the case of responses to target questions focused on seismicity, the resulting numerical uncertainty distribution are omitted from the table and from further analysis and discussion. This was deemed necessary because some participants provided quantile values that clearly demonstrated limited or negligible familiarity with the fundamentals of seismology and with the characteristics of induced seismicity sensu lato; and, in some cases, an individual's responses were internally incoherent with each other on related questions. The number of poorly informed participants was such as to preclude filtering some out to leave an adequate quorum, which would be the usual analyst's response in these circumstances (demonstrating also that a fully informed facilitator/analyst must be involved if nonsensical outcomes are to be avoided). 
Table 2 Median performance-weighted responses and $90 \%$ credible intervals provided by the experts to target questions

\begin{tabular}{|c|c|c|}
\hline Target question (unit of response) & Median value & $90 \%$ credible interval \\
\hline \multicolumn{3}{|c|}{$\begin{array}{l}\text { TQ19-21. (0-50 yrs) In the Capture phase of an } \\
\text { integrated CCS project, in which there is a } 50 \\
\text { year active phase followed by a purely storage } \\
\text { phase, what in your opinion is the likelihood of }\end{array}$} \\
\hline minor leakage $(1$ in $\mathrm{X})$ & 1 in 1 & 1 in 2,100 to 1 in 1 \\
\hline major leakage ( 1 in $\mathrm{X})$ & 1 in 125 & 1 in $1.0 \times 10^{6}$ to 1 in 10 \\
\hline catastrophic leakage ( 1 in $\mathrm{X})$ & 1 in 1,100 & 1 in $1.5 \times 10^{7}$ to 1 in 100 \\
\hline \multicolumn{3}{|c|}{$\begin{array}{l}\text { TQ22-24. (0-50 years) In the Transport phase of } \\
\text { an integrated CCS project, in which there is a } 50 \\
\text { year active phase followed by a purely storage } \\
\text { phase, what in your opinion is the likelihood of }\end{array}$} \\
\hline minor leakage $(1$ in $\mathrm{X})$ & 1 in 105 & 1 in 135,000 to 1 in 2.4 \\
\hline major leakage ( 1 in $\mathrm{X})$ & 1 in 1,050 & 1 in 550,000 to 1 in 31 \\
\hline catastrophic leakage ( 1 in $\mathrm{X})$ & 1 in 10,400 & 1 in $2.2 \times 10^{6}$ to 1 in 79 \\
\hline \multicolumn{3}{|c|}{$\begin{array}{l}\text { TQ25-27. (0-50 years) In the Injection phase of } \\
\text { an integrated CCS project, in which there is a } 50 \\
\text { year active phase followed by a purely storage } \\
\text { phase, what in your opinion is the likelihood of }\end{array}$} \\
\hline minor leakage ( 1 in $\mathrm{X})$ & 1 in 130 & 1 in 2,400 to 1 in 1.5 \\
\hline major leakage ( 1 in $\mathrm{X})$ & 1 in 1,290 & 1 in 23,700 to 1 in 7.5 \\
\hline catastrophic leakage ( 1 in $\mathrm{X})$ & 1 in 15,700 & 1 in 270,000 to 1 in 69 \\
\hline \multicolumn{3}{|c|}{$\begin{array}{l}\text { TQ28R-30R. In the first } 50 \text { years of an integrated } \\
\text { carbon sequestration project, what is the } \\
\text { likelihood of the following leakage scenarios [in } \\
\text { storage] ( } 1 \text { in } X \text {, where } X \geq 1 \text {; for example, } 1 \text { in } \\
100 \text { would represent a } 1 \% \text { likelihood)? }\end{array}$} \\
\hline minor leakage ( 1 in $\mathrm{X})$ & 1 in 13 & 1 in 1,520 to 1 in 1.4 \\
\hline major leakage ( 1 in $\mathrm{X})$ & 1 in 1,030 & 1 in 96,400 to 1 in 35 \\
\hline catastrophic leakage ( 1 in $\mathrm{X})$ & 1 in 10,300 & 1 in 1 million to 1 in 83 \\
\hline \multicolumn{3}{|c|}{$\begin{array}{l}\text { TQ31R-33R. From year } 51-499 \text { of an integrated } \\
\text { carbon sequestration project, what is the } \\
\text { likelihood of the following leakage scenarios [in } \\
\text { storage] ( } 1 \text { in } X \text {, where } X \geq 1 \text {; for example, } 1 \text { in } \\
100 \text { would represent a } 1 \% \text { likelihood)? }\end{array}$} \\
\hline minor leakage ( 1 in $\mathrm{X})$ & 1 in 9.9 & 1 in 2,070 to 1 in 2 \\
\hline major leakage ( 1 in $\mathrm{X})$ & 1 in 890 & 1 in 16,100 to 1 in 57 \\
\hline catastrophic leakage ( 1 in $\mathrm{X})$ & 1 in 11,300 & 1 in 1 million to 1 in 595 \\
\hline
\end{tabular}

Notes: $\mathrm{R}$ in question number denotes re-elicitation ${ }^{1}$;

${ }^{1}$ Exact meaning should not be ascribed to the precision of these reported results they should be regarded as indicative. 
Table 2 Median performance-weighted responses and 90\% credible intervals provided by the experts to target questions (continued)

\begin{tabular}{|c|c|c|}
\hline Target question (unit of response) & Median value & $90 \%$ credible interval \\
\hline \multicolumn{3}{|l|}{$\begin{array}{l}\text { TQ34R-36R. From year } 500 \text { onwards of an } \\
\text { integrated carbon sequestration project, what is } \\
\text { the likelihood of the following leakage scenarios } \\
\text { [in storage] ( } 1 \text { in } X \text {, where } X \geq 1 \text {; for example, } 1 \\
\text { in } 100 \text { would represent a } 1 \% \text { likelihood)? }\end{array}$} \\
\hline minor leakage ( 1 in $\mathrm{X})$ & 1 in 27 & 1 in 8,340 to 1 in 2 \\
\hline major leakage ( 1 in $\mathrm{X})$ & 1 in 1,200 & 1 in 172,000 to 1 in 100 \\
\hline catastrophic leakage ( 1 in $\mathrm{X})$ & 1 in 12,500 & 1 in 1 million to 1 in 1,020 \\
\hline \multicolumn{3}{|l|}{$\begin{array}{l}\text { TQ40R-42R: In a typical saline aquifer storage } \\
\text { site, what is the likelihood of major } \mathrm{CO}_{2} \text { leakage } \\
\text { that would result in measurable negative } \\
\text { environmental impact or adverse public health } \\
\text { impact in each of the time periods ( } 1 \text { in } \mathrm{X} \text {, where } \\
\mathrm{X} \geq 1 \text {; for example, } 1 \text { in } 100 \text { would represent a } \\
1 \% \text { likelihood)? }\end{array}$} \\
\hline $0-50$ yrs & 1 in 1,030 & 1 in 71,900 to 1 in 33 \\
\hline $51-499$ yrs & 1 in 1,050 & 1 in 1 million to 1 in 61 \\
\hline $500+y r s$ & 1 in 1,140 & 1 in 1 million to 1 in 103 \\
\hline $\begin{array}{l}\text { TQ48: What is the worldwide capacity for } \\
\text { geological } \mathrm{CO}_{2} \text { sequestration in saline aquifers } \\
\left(\mathrm{GtCO}_{2}\right) \text { ? }\end{array}$ & $28 \mathrm{Gt}$ & $0.1 \mathrm{Gt}$ to $76,000 \mathrm{Gt}$ \\
\hline $\begin{array}{l}\text { TQ49: What is the ultimate } \mathrm{CO}_{2} \text { sequestration } \\
\text { capacity in solution as a percent }(\%) \text { of a deep } \\
\text { saline aquifer }(\%) \text { ? }\end{array}$ & $1.2 \%$ & $0.2 \%$ to $33 \%$ \\
\hline $\begin{array}{l}\text { TQ50: What percentage of a theoretical repository } \\
\text { capacity for a reasonable quality saline aquifer } \\
\text { would you generally expect could be accessed by } \\
\text { carbon dioxide placement using horizontal wells } \\
(\%) \text { ? }\end{array}$ & $7.5 \%$ & $1.0 \%$ to $76 \%$ \\
\hline $\begin{array}{l}\text { TQ51: In a } \mathrm{CO}_{2} \text { injection scheme in deep saline } \\
\text { aquifer ( } \sim \mathrm{MtCO}_{2} \text { /year), what is the modal } \\
\text { distance from the injection well that is likely to be } \\
\text { affected by salt precipitation (metres)? }\end{array}$ & $7.6 \mathrm{~m}$ & $1 \mathrm{~m}$ to $175 \mathrm{~m}$ \\
\hline
\end{tabular}

Notes: $\mathrm{R}$ in question number denotes re-elicitation ${ }^{1}$;

${ }^{1}$ Exact meaning should not be ascribed to the precision of these reported results they should be regarded as indicative.

Gerstenberger et al. (2015) found that hazard and risk assessments related to induced seismicity are still in the early stages of development and that further research is needed to better understand these risks. Even though the overall number of $\mathrm{CO}_{2}$ injection projects is growing, White and Foxall (2016) point out that relatively few investigations have been undertaken into the seismic behaviour of these fields. They suggest that much more observational data and field experience is clearly necessary and should be made broadly-accessible to independent research groups to solicit the best analyses and insights. Given improved understanding of induced seismicity will likely evolve as injection field experience grows, this is an issue for a focused elicitation involving knowledgeable subject matter specialists in this particular field. 
Figure 5 Range graph plot with individual expert responses, performance-weighted responses and equal-weighted responses (see online version for colours)

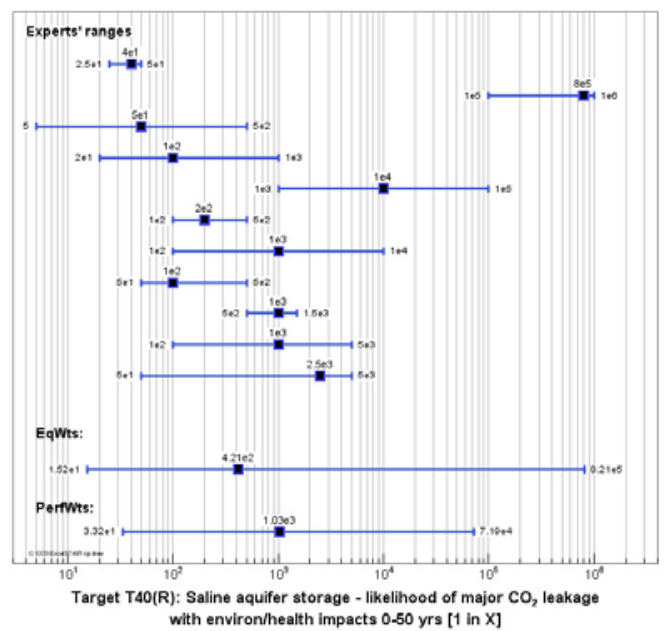

(a)

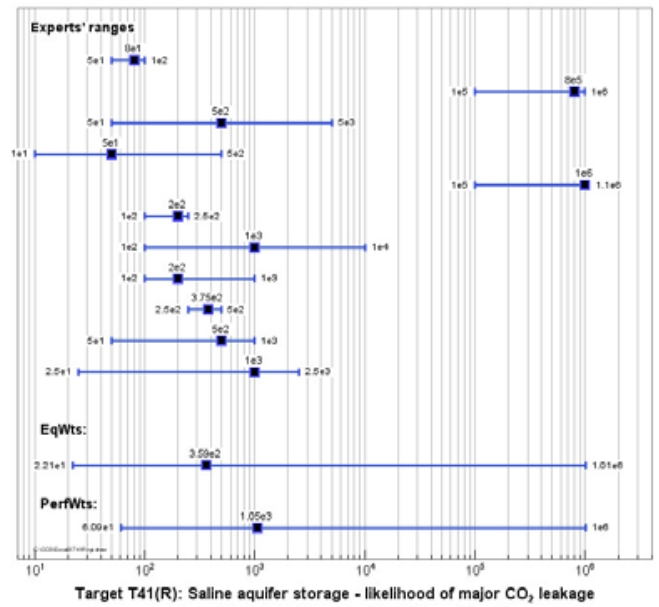

with environ/health impacts 51 . $499 \mathrm{yrs}[1$ in X]

(b)

Notes: T40-42Rev: in a typical saline aquifer storage site, what is the likelihood of major $\mathrm{CO}_{2}$ leakage that would result in measurable negative environmental impact or adverse public health impact in the (a) 0-50 year (b) 51-499 year (c) $>500$ year time period ( 1 in $X$, where $X \geq 1$; for example, 1 in 100 would represent a $1 \%$ likelihood)? 
Figure 5 Range graph plot with individual expert responses, performance-weighted responses and equal-weighted responses (continued) (see online version for colours)

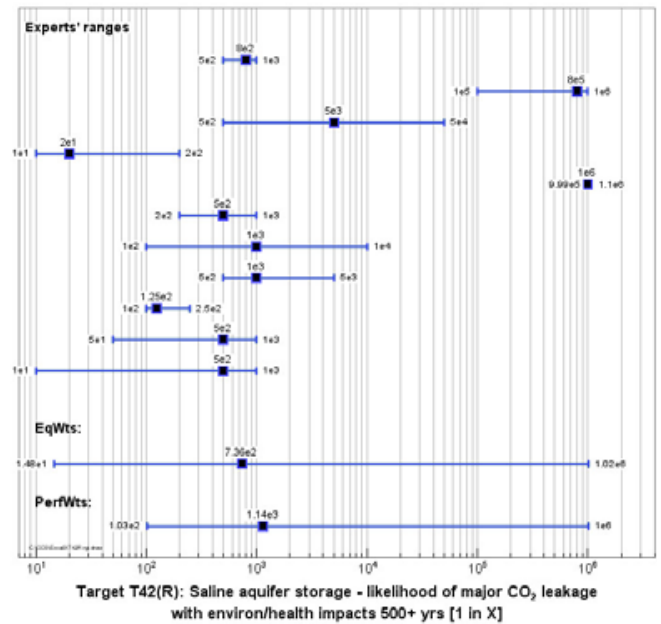

(c)

Notes: T40-42Rev: in a typical saline aquifer storage site, what is the likelihood of major $\mathrm{CO}_{2}$ leakage that would result in measurable negative environmental impact or adverse public health impact in the (a) 0-50 year (b) 51-499 year (c) $>500$ year time period ( 1 in $X$, where $X \geq 1$; for example, 1 in 100 would represent a $1 \%$ likelihood)?

Target questions asking the likelihood of a measurable negative environmental impact or adverse public health impact at five levels of hazard severity are also excluded from the analysis: pooled solutions about these impacts were uninformative and clear dichotomies between individuals' responses suggest there were ambiguities of understanding within the group. It was not possible to resolve these fully in the re-elicitation that was undertaken and these issues therefore remain open for further investigation.

a Likelihood of minor, major or catastrophic $\mathrm{CO}_{2}$ leakage.

TQ19-36R: in each of the four chain components of an integrated CCS project, in which there is a 50 year active phase followed by a purely storage phase, what in your opinion is the likelihood ( 1 in $\mathrm{X})$ of:

1 minor leakage

2 major leakage

3 catastrophic leakage.

Experts began with a common understanding of leakage scenarios. Capture and transport leakage likelihood uncertainty from performance weight (PW) solutions (on log scales) increases significantly from minor to major to catastrophic leakage (TQ19-24, Table 1). For injection, leakage likelihood uncertainty (on log scales) also 
increases overall from minor to major to catastrophic leakage, although much less so than for capture or transport (TQ25-27).

The median response was essentially the same for the likelihood of storage leakage

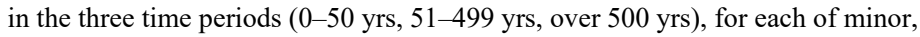
major and catastrophic event types ( $>1$ in $30 ; \sim 1$ in 103; avg $\sim 1$ in 11,300) (TQ28R-TQ36R, Table 1). The PW upper likelihood limit of minor leakage was essentially the same in all time periods ( $>1$ in 2 ), as was the lower likelihood limit for catastrophic leakage (1 in 106). However, experts' likelihood uncertainty distributions suggest that 'two schools of thought' exist, with response groupings indicating that some experts suggest higher likelihoods and others who suggest much lower likelihoods (supplementary material). Experts' PW uncertainty was greatest for the likelihood of catastrophic leakage in 0-50 year operating period.

b Likelihood of major leakage in a saline sequestration site that would result in measurable effects on the environment or human health.

$T Q 40 R-42 R$ : in a typical saline aquifer storage site, what is the likelihood of major $\mathrm{CO}_{2}$ leakage that would result in measurable negative environmental impact or adverse public health impact in each of the time periods ( 1 in $X$, where $X \geq 1$; for example, 1 in 100 would represent a $1 \%$ likelihood)?

In this triplet of questions, experts understood that the site would be properly selected, characterised and designed; that major leakage would require an intervention to mitigate effects; and that a measurable effect on the environment or human health would be detectable. In each time period, the median likelihood is essentially the same (1 in 103) (TQ40-42R, Table 1; Figures 5-6). Experts' views were divided into groups expressing higher and much lower likelihoods over all timeframes (Figure 5; see also supplementary material). PW solutions are tighter and thus more informative than equal weight (EW) solutions for the two longer timescales.

c Storage capacity and injectivity

$T Q 48$ : what is the worldwide capacity for geological $\mathrm{CO}_{2}$ sequestration in saline aquifers $\left(\mathrm{GtCO}_{2}\right)$ ?

The uncertainty distribution for the worldwide capacity for geological sequestration in saline aquifers is wide, with median response $28 \mathrm{Gt}$ and $90 \%$ credible range from $0.1 \mathrm{Gt}$ to $76,000 \mathrm{Gt}$ (TQ48, Table 1). PW findings display a lower median than EW pooled responses.

TQ49: what is the ultimate $\mathrm{CO}_{2}$ sequestration capacity in solution as a percent (\%) of a deep saline aquifer?

The uncertainty distribution for sequestration capacity in solution as a percent of the aquifer is also wide: median $1.2 \% ; 0.2 \%$ to $33 \%$ credible range (T49, Table 1 ). Responses to this question suggest two schools of thought about this target item (supplementary material). 
TQ50: what percentage of a theoretical repository capacity for a reasonable quality saline aquifer would you generally expect could be accessed by carbon dioxide placement using horizontal wells $(\%)$ ?

The median percentage is $7.5 \%$, approximately half the EW solution but uncertainty distributions are quite similar (TQ50, Table 1; supplementary material).

TQ51: In a $\mathrm{CO}_{2}$ injection scheme in deep saline aquifer $\left(\sim 1 \mathrm{MtCO}_{2} /\right.$ year $)$, what is the modal distance from the injection well that is likely to be affected by salt precipitation (metres)?

Experts' judgement on the modal distance from the injection well that is likely to be affected by salt precipitation indicates a lower median distance $(\sim 7.6 \mathrm{~m})$ and smaller uncertainty bounds than EW (TQ51, Table 1; supplementary material).

Figure 6 Composite plot of comparative piece-wise uncertainty distributions (see online version for colours)

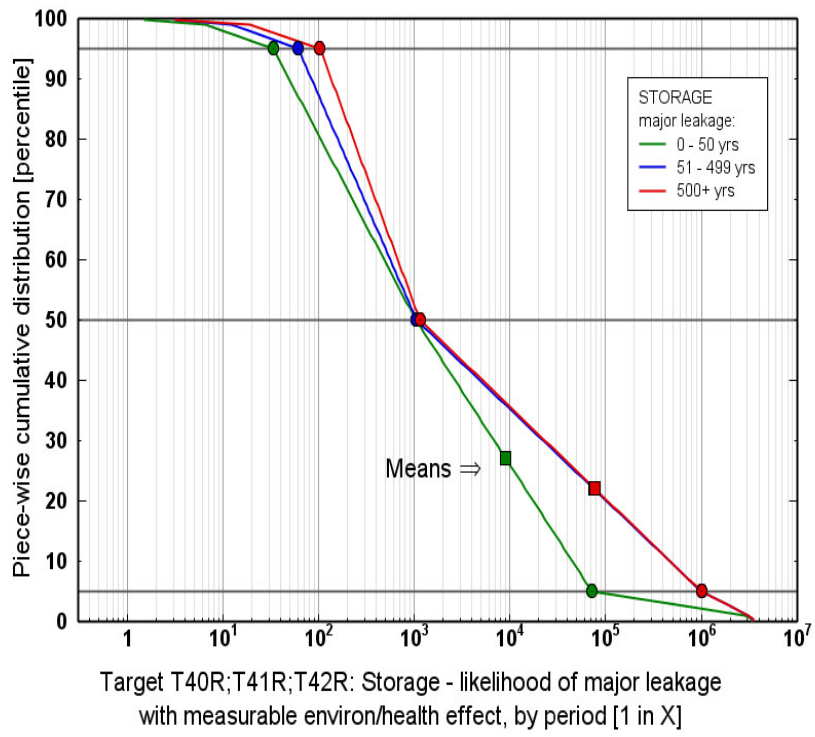

Notes: T40-T42Rev: this triplet of questions concerns the likelihood of major $\mathrm{CO}_{2}$ leakage in a typical saline aquifer that would result in significant effects on the local environment or human health, in each of three time periods: $0-50 \mathrm{yrs}$; 51-499 yrs; and over 500 yrs. In a typical saline aquifer storage site, what is the likelihood of major $\mathrm{CO}_{2}$ leakage that would result in measurable negative environmental impact or adverse public health impact in each of the time periods ( 1 in $X$, where $X \geq 1$; for example, 1 in 100 would represent a $1 \%$ likelihood)? 
Figure 7 Mean expert likelihood rating of 29 potential hazards, including standard error as a measure of uncertainty in expert opinion (see online version for colours)

\section{Likelihood Hazard Rating}

- Mean +/-SE

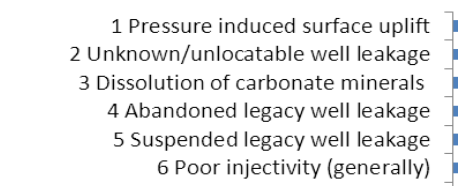

7 Known oil and gas operating well leakage

8 Re-opening of existing fractures

9 Injection - loss of wellbore integrity

10 CCS Injection well leakage

11 Reactions with ductile shale caprock

12 Reduced injectivity due to salt precipitation

13 Seal system integrity due to unexpected geology

14 Insufficient storage capacity

15 Reactivation of existing fault

16 Deterioration and breach of capillary seals

17 CCS Monitoring well leakage

18 Unexpected intensely fractured seal zones

19 Unexpected pressures, stresses or temperatures

20 Unexpected non-sealing faults

21 Injection devmt of vertical hydraulic fractures

22 Induced seismic activity $M>4$

23 Reduced injectivity due to plume-oil interaction

24 Induced vertical caprock fracturing

25 Well shearing

26 Injection breach of caprock (not hydr fracturing)

27 Induced thermal caprock fracture

28 Creation of a new fault

29 Wellbore - breach of multiple barriers

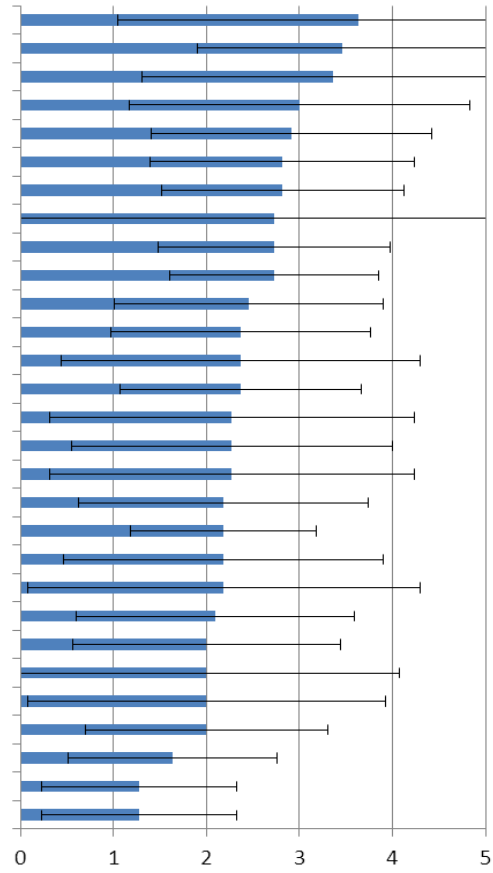

Notes: Ratings range from: improbable (1); unlikely (2); possible (3); likely (4); probable

(5).

\subsection{Likert scale rating of likelihood and severity of hazards}

Experts' judgement was elicited for the likelihood and severity of 29 hazards in well leakage, injection and intrinsic and induced storage circumstances. The impact was understood to be physical damage to infrastructure or the geological formation. The mean rating for each hazard, with standard error as a measure of uncertainty in expert opinion, is provided in Figures 7-8. Results categorised by the four hazards groups are provided in the supplementary material. In some cases, the elicitation description was more specific than the features, events and processes considered in the unstructured expert elicitation (Polson et al., 2012). Hazard risk ranking was calculated as likelihood $\times$ severity of experts' mean response (Figure 9). Only the unknown and unlocatable well hazard scored as high risk based on the cutoffs used by Polson et al. (2012) (>10). 
Figure 8 Mean expert rating of the severity of twenty-nine potential hazards should they occur, including standard error as a measure of uncertainty in expert opinion (see online version for colours)

\section{Severity Hazard Rating}

- Mean +/-SE

1 Seal system integrity due to unexpected geology

2 Unexpected non-sealing faults 3 Unexpected intensely fractured seal zones 4 Creation of a new fault

5 Wellbore - breach of multiple barriers 6 Induced vertical caprock fracturing 7 Injection devmt of vertical hydraulic fractures

8 Induced seismic activity $M>4$ 9 Reactivation of existing fault Lo Injection - Breach of caprock (not hydr fracturing) 11 Deterioration and breach of capillary seals 12 Unknown/unlocatable well leakage 13 Well shearing 14 Loss of wellbore integrity 15 Re-opening of existing fractures 16 Abandoned legacy well leakage 17 Induced thermal caprock fracturing 18 Unexpected insufficient storage capacity 19 CCS Injection well leakage 20 Unexpected pressures, stresses or temperatures 21 Suspended legacy well leakage 22 Poor injectivity (generally) 23 Known oil and gas operating well leakage 24 Reactions with ductile shale caprock 25 Reduced injectivity due to salt precipitation 26 CCS Monitoring well leakage 27 Reduced injectivity due to plume-oil interaction 28 Dissolution of carbonate minerals 29 Pressure induced surface uplift

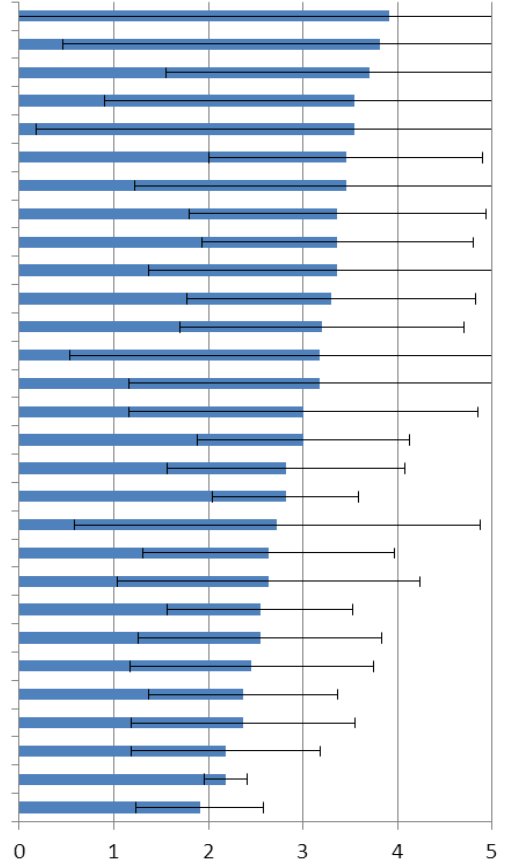

Notes: Ratings range from: light (1); serious (2); major (3); catastrophic (4); multi-catastrophic (5).

Combined likelihood and severity of experts' mean response is summarised in a risk matrix form (Figure 10). It is interesting to note that the display of experts' mean responses within the risk matrix does not necessarily match risk ranking values. For instance, reduced injectivity due to plume oil interaction is low risk quantitatively and medium risk on the matrix; similarly, unknown and unlocatable wells scored high risk quantitatively and medium risk on the matrix. This illustrates the differences that can arise as a function of the cut-off value given to risk categories. 
Figure 9 Risk ranking $(1 \times \mathrm{s}$ of mean rating) for twenty nine hazards in well leakage, injection, intrinsic storage and induced storage circumstances (see online version for colours)

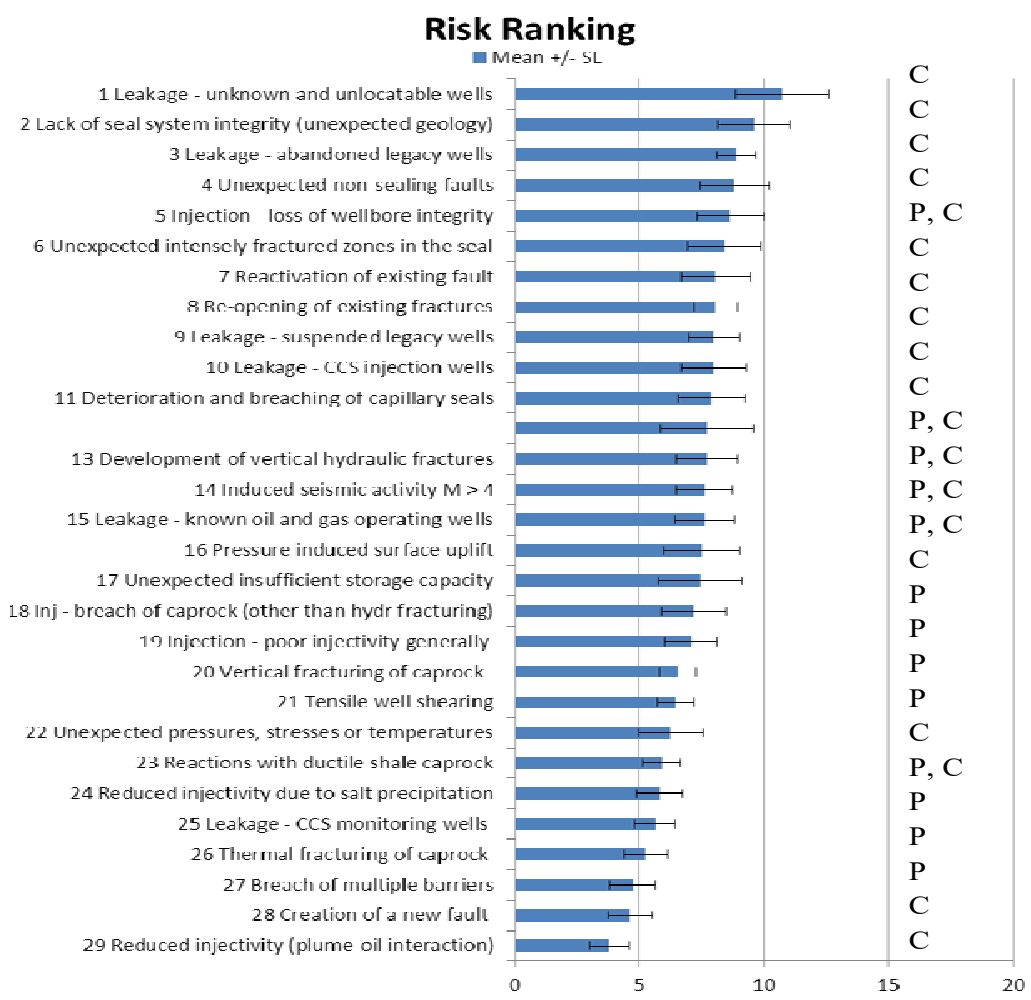

Notes: $1 \times \mathrm{s}$ value of less than 5 is considered low risk; hazards in the range $5 \leq 1 \times \mathrm{s}<10$ are medium risk; $10 \leq 1 \times \mathrm{s}<20$ hazards are high risk; and $\geq 20$ are very high risk. Column on right indicates principal risk category: containment $(\mathrm{C})$ or performance $(\mathrm{P})$.

\section{Discussion}

In 2015, an international panel of recognised authorities from both academia and research institutes participated in a structured elicitation on risk and attendant uncertainties in aspects of CCS. Experts represent diverse backgrounds in technical risk issues of CCS, where the overarching goals of deployment have always focused on safety and environmental protection, thus preventing health or environmental impacts in the short and long term. 
Figure 10 Risk matrix indicating mean response likelihood and severity combination for all hazards (see online version for colours)

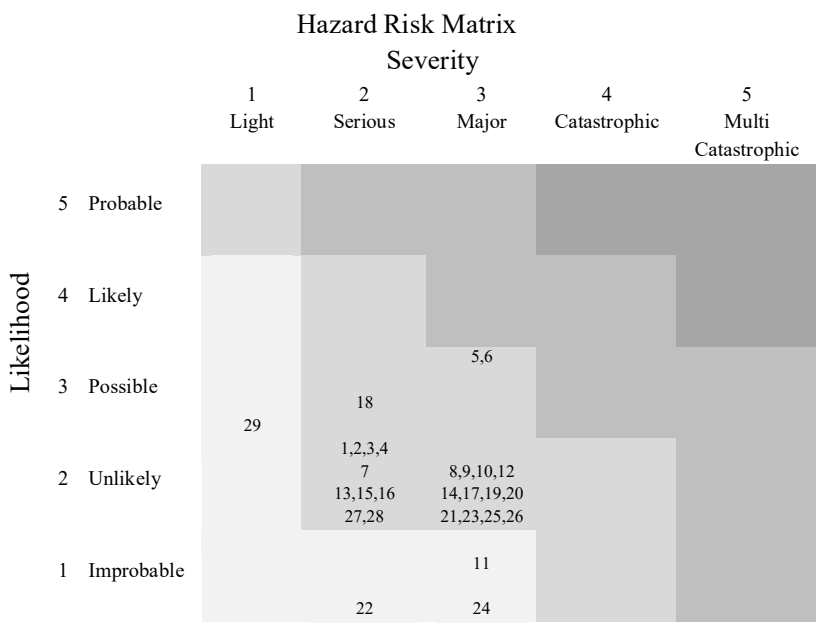

Notes: Top row of each square - well hazards: 1 ccs injection, 2 ccs monitoring, 3 known oil and gas operating wells, 4 suspended legacy wells, 5 abandoned legacy wells, 6 unknown and unlocatable wells; 2nd row - injection hazards: 7 poor injectivity, 8 loss wellbore integrity, 9 vertical hydraulic fractures, 10 breach of caprock (other than hydraulic fracturing), 11 breach of multiple barriers; 12 tensile well shearing; 3rd row - intrinsic storage hazards: 13 unexpected insufficient storage capacity, 14 unexpected non sealing faults, 15 unexpected pressures, stresses or temperatures, 16 reactions with ductile shale caprock, 17 deterioration breach of capillary seals, 18 dissolution of carbonate minerals, 19 unexpected intensely fractured zones in the seal, 20 lack of integrity in the seal system due to unexpected geology; 4th row - induced storage hazards: 21 vertical caprock fracturing, 22 thermal caprock fracturing, 23 re-opening of existing fractures, 24 creation of new fault, 25 reactivate existing fault, 26 induced seismic event $\mathrm{m}>4$, 27 reduced injectivity due to plume-oil interaction, 28 reduced injectivity due to salt precipitation, 29 pressure induced surface uplift.

With a focus on saline aquifer geologic sequestration, target questions considered both performance and containment issues in injection and storage chain components of integrated projects and low probability high impact events. A limited number of questions considered capture and transport chain activities and other storage options. Target questions are not intended to be used for risk assessment of any specific project. Rather, this exercise was a first attempt to quantify an expert panel's opinions about selected technical, environmental and human health hazard and risk issues related to CCS that can be anticipated to arise during CCS project assessment, review and approval processes.

Eleven international experts, a number considered adequate to obtain meaningful results (Colson and Cooke, 2017), agreed a priori about $\mathrm{CO}_{2}$ leakage scenarios; injection and storage activity boundaries; that the envisioned integrated saline sequestration project would use transport by pipeline; and the storage site, developed in a low to medium 
population density area, would be properly selected, characterised and designed. Furthermore, it was understood that wellbores would be properly completed and sealed for the duration of the storage period.

Previously, Pawar et al. (2015) provided a thorough review of advances in methodologies for risk assessment and risk management of $\mathrm{CO}_{2}$ sequestration. Using the same typology, this discussion considers findings related to performance and containment hazard/risk issues (see also Sarkarfarshi et al., 2019).

\subsection{Global capacity and performance risk}

The backdrop for CCS as a mitigation technology for climate change requires global geological storage capacity. In broad terms, the expert panel's median best estimate for sequestration in saline aquifers indicates room for approximately $28 \mathrm{GtCO}_{2}$ (uncertainty $\left.0.1-7.6 \mathrm{E}+04 \mathrm{GtCO}_{2}\right)(\mathrm{TQ} 48$, Table 1). This compares with the 2005 IPCC Special Report on CCS that included a worldwide lower estimate of $1,000 \mathrm{GtCO}_{2}$ and upper estimate uncertain, possibly $104 \mathrm{GtCO}_{2}$ (IPCC, 2005, p.221). Within the intervening period, the 2015 expert panel appears to have a different judgement for this potential. However, for the 2DS the IEA (2016) suggested CCS deployment would see approximately $94 \mathrm{GtCO}_{2}$ captured and stored through 2050, storage that is within the expert panel's credible range.

The fraction of pore volume available and accessible for storage by $\mathrm{CO}_{2}$ injection is estimated as the storage resource (Bachu, 2015; US Department of Energy, 2015). Provided here as further points of reference and with variable levels of detail, several jurisdictions have published national and regional storage atlases: US Department of Energy (2015), North American Carbon Atlas Partnership (2012), the Norwegian Sea (Norwegian Petroleum Directorate, 2013) and Brazil (Ketzer et al., 2014). An online storage resource catalogue has been developed in the UK (The Crown Estate and British Geological Survey, 2016). Consoli and Wildgust (2017) present the 'Global Storage Portfolio', a collated summary of storage assessments worldwide, including both deep saline sequestration and EOR formations. Indeed, an effort to quantify the worldwide capacity for geologic sequestration was identified as a necessary activity, with $\mathrm{CO}_{2}$ storage sites potentially designated strategic national assets (IEA, 2015). Selected estimates for saline formation storage resource are provided in Table 3 .

Using these geological resources effectively depends on managing performance risks for injectivity and storage capacity. CCS projects are expected to achieve injection rates that support storage objectives. For example, large scale integrated saline aquifer sequestration projects are generally conceived to inject upwards of $1 \mathrm{Mt} \mathrm{CO}_{2}$ each year for the duration of their operating period.

Experts' views on hazard issues in the performance risk of injectivity were elicited using three question formats. Based on pairwise preference semi-quantitative ranking, experts held similar views regarding the reactivity of five minerals with $\mathrm{CO}_{2}$ in pure supercritical and dissolved state (Figure 4). From most to least reactive under the two defined conditions, rank order unambiguously located calcite and quartz at the top and bottom rank order of reactivity.

Experts also provided quantitative judgements for the modal distance that could be expected for salt precipitation. This reaction can cause a reduction in permeability and thereby have a negative effect on injectivity and pressure. Experts' performance weight median response was approximately $7.6 \mathrm{~m}$ from the wellbore, with a $90 \%$ credible 
uncertainty range from 1 to $175 \mathrm{~m}$ (TQ51, Table 1). As a point of reference, simulations for the Shell Quest sequestration project located in the Western Canadian Sedimentary Basin (Alberta, Canada), indicated an approximate effect of $15 \mathrm{~m}$ (Shell Canada Limited, 2011a).

Table $3 \quad \mathrm{CO}_{2}$ saline formation storage resource estimates (potential volume)

\begin{tabular}{|c|c|c|c|}
\hline \multirow{2}{*}{ Country } & \multicolumn{3}{|c|}{ Storage resource estimates $(G t)$} \\
\hline & Low & Medium & High \\
\hline $\begin{array}{l}\text { USA (US Department of Energy, } \\
\text { 2015) }\end{array}$ & $\begin{array}{l}2,379(2015) \\
1,610(2012)\end{array}$ & 8,328 & $\begin{array}{l}21,633(2015) \\
20,155(2012)\end{array}$ \\
\hline $\begin{array}{l}\text { Canada (North American Carbon } \\
\text { Atlas Partnership, 2012) }\end{array}$ & 28 & 110 & 296 \\
\hline $\begin{array}{l}\text { Mexico (North American Carbon } \\
\text { Atlas Partnership, 2012) }\end{array}$ & 100 & & \\
\hline $\begin{array}{l}\text { Norway (Norwegian Petroleum } \\
\text { Directorate, 2013) }\end{array}$ & & 4.4 & \\
\hline IEA projection for CCS (IEA, 2016) & & $\begin{array}{l}\text { Cumulative } 94 \\
\text { by } 2050\end{array}$ & \\
\hline
\end{tabular}

Experts also assessed the likelihood and severity of several injection hazards using a Likert-scale question format. Risk ranking was calculated as mean rated likelihood multiplied by mean rated severity (Figures 7-8). With the exception of injection hazard 'loss of wellbore integrity' which ranked 5th of 29 performance and containment hazards, all other injection hazards did not rank high: CCS injection well leakage (9th); injection - development of vertical hydraulic fractures (12th); injection - breach of caprock (other than hydraulic fracturing) (17th); poor injectivity (generally) (18th); tensile well shearing (21st); reduced injectivity due to salt precipitation (24th); and reduced injectivity due to plume-oil interaction (29th). Some of these performance hazards are also considered containment hazards (Figure 9).

Performance risk for CCS also concerns achieving storage efficiency and capacity in the project's geologic formation (Bachu, 2015; IEA, 2013; Pawar et al., 2015; Sarkarfarshi et al., 2019). Both Bachu (2015) and the IPCC ten years earlier (IPCC, 2005), suggested that a range is expected depending on the storage site characteristics and temporal considerations.

In answering a question focused on solubility trapping, experts' median response suggested approximately $1.2 \%$ ultimate sequestration capacity, with performance weight uncertainty ranging from approximately $0.2 \%$ to $33 \%$ (TQ49, Table 1 ).

Experts provided a higher estimate of the practical repository capacity that could be accessed using horizontal wells drilling strategy: $7.5 \%$ of pore space replaced with supercritical $\mathrm{CO}_{2}$, with uncertainty ranging from about $1 \%-75 \%$ (TQ50, Table 1). The use of this technology was envisioned in 2005 as a way to increase the injection rate while drilling fewer wells (IPCC, 2005). The technology used to place $\mathrm{CO}_{2}$ in the reservoir has a practical impact on the amount of $\mathrm{CO}_{2}$ that can be injected in a given period of time. As shown in van der Meer (1993), injection rate must decrease over time if the maximum allowable injection pressure is not to be exceeded. This puts some practical limits on how much $\mathrm{CO}_{2}$ can be placed in the reservoir with a given technology.

Furthermore, unexpected insufficient storage capacity as a performance hazard was assessed in the Likert scale question format, ranking 14th in hazard likelihood and 18th in 
severity, with relatively low uncertainty compared to other hazards (Figures 7-8); risk ranking was 15th of 29 risks (Figure 9). Risk ranking of other storage related performance hazards includes dissolution of carbonate minerals (11th); pressure induced surface uplift (19th); unexpected pressures, stresses, temperatures (22nd); and reactions with ductile shale caprock (23rd).

Finally, while injectivity and intrinsic and induced storage capacity issues may limit project performance, sequestration sites could also be limited by economic or regulatory constraints (Bachu, 2015; Dixon et al., 2015), issue areas potentially of interest to a future elicitation.

\subsection{Focus on human health and the environment}

Ensuring public health and environmental protection are important goals in project planning, implementation and eventual decommissioning of CCS sites. Experts responded to general and specific questions related to this important consideration.

In general terms, the experts did not differentiate relative long-term risk between three storage options of enhanced oil recovery (EOR), coalbed methane (CBM) and saline aquifer sequestration (Figure 2). This finding is of interest in light of the current prominence of EOR, accounting for approximately $76 \%$ of operating projects and $81 \%$ of the capture rate worldwide (GCCSI, 2018; MIT, 2018).

The experts also compared technical, environmental and health risk in capture, transport, injection and storage in general terms. Relative risks for the environment or technical domains were not strongly differentiated within each of these activities, although transport by pipeline was ranked as the lowest risk [Figure 1(a)]. For technical as compared to health risk, strong evidence separated health risk rankings of capture and injection relative to transport and storage. Storage was seen as a greater technical risk than health risk [Figure 1(b)]. Further, experts' rank scores clearly differentiated capture as a greater potential health risk than environmental risk [Figure 1(c) and supplementary material]; injection and transport were viewed of equal potential risk to the environment and health, with injection a greater risk to both. Storage was viewed as a greater potential risk to the environment than health. These findings could reflect experts' range of technical expertise in CCS compared with more limited expertise in potential health impacts of CCS.

With respect to elicited distinct causes of local health or environmental hazards, expert rankings did not discriminate between brine/gas migration in the subsurface/near surface environment, explosive $\mathrm{CO}_{2}$ release to the surface and seismic event $>\mathrm{M} 5$ (Figure 3). However, caprock integrity loss due to hydraulic fracturing was ranked a lower relative hazard. In Likert-scale format, likelihood and severity of migration (as several listed containment hazards), seismic event $>\mathrm{M} 4$ (a different cutoff than the relative risk question format) and caprock fracture hazards (as vertical caprock fracturing, thermal caprock fracturing and breach of caprock (other than hydraulic fracturing), were also rated. Within the list of 29 hazards, none of these ranked a high risk (Figures 9-10), although there was a range of uncertainty in the group's judgement of each risk (Figure 9). 


\subsection{Performance and containment - leakage}

Wide ranging injection and storage performance and containment hazards have the potential to create the conditions for $\mathrm{CO}_{2}$ leakage during $\mathrm{CCS}$ operations and long term sequestration period. Leakage to the biosphere could occur though channels associated with a borehole or through a geological fault area [Paulley et al. (2012), cited in Jones et al. (2015)].

In assessing the likelihood and severity of 29 hazards related to well leakage, injection and intrinsic and induced storage circumstances, the mean ratings of the expert panel did not surpass level 4 (likely, catastrophic) for any hazard and the greatest uncertainty did not necessarily match the highest mean rated hazard (Figures 7-8). One hazard, development of vertical caprock fractures in injection, had high uncertainty for both likelihood and severity. On the other hand, as both a performance and public perception risk issue, pressure induced surface uplift had the highest mean likelihood and lowest severity of the 29 hazards, with a risk ranking of 17th overall (Figure 9).

The risk ranking and risk matrix (Figures 9-10) emulate the findings of Bowden et al. (2013a) and Bowden et al. (2013b) in their consideration of the Weyburn-Midale EOR project (Saskatchewan, Canada). In the present study, unknown and unlocatable wells were the greatest containment risk and abandoned legacy well leakage ranked 3rd (Figure 9). Similarly, Quintessa's database of Features, Events and Processes (Quintessa Ltd., 2018) suggested it would be difficult for project developers to 'detect a substandard well abandonment before the beginning of $\mathrm{CO}_{2}$ injection to the designed reservoir', particularly an unknown well within the assessed storage zone. Several well leakage hazards ranked high on the list of 29 hazards and as both a performance and containment risk, 'injection - loss of wellbore integrity' ranked 4th overall.

The expert panel also completed quantitative judgements on the likelihood of leakage scenarios during each chain component of a large scale sequestration project (TQ19-36R, Table 2). Leakage was interpreted as 'detectable'. During the $0-50$ year operating period, some experts' judged minor leakage as a virtual certainty in capture and transport, with likelihood uncertainty increasing significantly from minor to major to catastrophic events (TQ19-24, Table 2). Koornneef et al. (2012) found the highest failure scenario flow rate was for the transport activity. Based on existing studies from natural gas pipeline incidents, Duncan and Wang (2014) summarised the likelihood of failure of $\mathrm{CO}_{2}$ pipelines at $1.2 \times 10^{-4}$ to $6.1 \times 10^{-4} \mathrm{~km}^{-1} \mathrm{yr}$. The study suggested this has been overestimated by 2-3 orders of magnitude for events that could result in fatalities or injuries. As the present panel of experts may be less well versed in issues of capture and transport than injection and storage, further elicitation with specialists in these particular domains could assist with quantifying uncertainty judgements.

Uncertainty for the likelihood of leakage during injection increased, but much less markedly than for capture and transport, with an order of magnitude increase in probability between minor, major and catastrophic events (TQ25-27, Table 2). Previously, Bachu and Watson (2009) reviewed failures for $\mathrm{CO}_{2}$ and acid gas well injection in Alberta, Canada, finding that the incidence of well failures was greater before 1994 regulations and suggested that drilled for purpose $\mathrm{CO}_{2}$ injection wells, under an appropriate regulatory framework, will reduce and prevent well failures. 
Given the protracted temporal dimensions of CCS, with sequestration anticipated for periods of 1,000 years or more, numerical uncertainty distributions for leakage likelihood in storage were broken down and elicited for the $0-50 \mathrm{yr}$ operating period, as well as for 51-499 yr and 500+ year storage periods. Experts' responses suggest a similar median likelihood (with marked decrease) for each of minor, major and catastrophic leakage in each of the three time periods ( $>1$ in $30 ; 1$ in $103 ; 1$ in 104 , respectively) (Table 2). Elicitation findings also appear to suggest some difference of opinion exists among the experts. Response groupings are evident in this analysis, with some experts suggesting higher likelihoods and others much lower likelihoods (supplementary material). This is especially evident for minor leakage across all timescales.

Leakage amounts, rates and probabilities have been estimated previously by a number of investigators (supplementary material). Pawar et al. (2015) provide several examples of leakage risk assessment applications, including a quantitative leakage likelihood assessment for aspects of the Otway Project, Australia (Watson, 2014). For more than ten risk events, a normalised quantitative risk quotient was determined by experts, as a function of probability and impact relative to the target risk leakage limit of $1 \%$ over 1,000 years.

Previous research suggested that the risks associated with injected $\mathrm{CO}_{2}$ will likely decline with time and on longer timescales $\left(10^{3}-10^{4} \mathrm{yr}\right)$ (Benson, 2007; Koornneef et al., 2012). $\mathrm{CO}_{2}$ should become permanently immobilised, though the percent trapping contribution is expected to vary over time: primary mechanisms in the operating period (structural, stratigraphic and hydrodynamic trapping); extending to secondary mechanisms in closure and post-closure period (residual phase, solubility and mineral trapping mechanisms). While performance is focused on achieving injection targets and storage capacity, poor containment could permit the $\mathrm{CO}_{2}$ plume to extend to geologic formations that were not well assessed, with an unknown level of attendant risk. Indeed, $\mathrm{CO}_{2}$ will continue to migrate for some time after injection due to residual pressure gradients. This allows the $\mathrm{CO}_{2}$ to come in contact with a great area of the caprock, in time making the likelihood of encountering a leakage pathway higher. Nevertheless, the effects of re-release could be time-dependent, with less serious climate effects if occurring in the long term (IPCC, 2005; Wilson et al., 2003). In Alberta, Canada, Shell's Quest sequestration project documentation estimated zero leakage from storage (Shell Canada Limited, 2011b).

The elicitation delved deeper into experts' views regarding the likelihood of major leakage in a saline sequestration site that would result in measurable effects on the environment or human health. The term 'measurable' was understood to represent 'detectable'. In this triplet of questions, experts' judgement of the risk of leakage was essentially the same over the three time periods, that is, 1 in 1,000 or $0.1 \%$ (TQ40-42R, Table 1). Previously and as a potentially extreme effect, Roberts et al. (2011) suggested the risk of death from exposure to $\mathrm{CO}_{2}$ leakage from natural $\mathrm{CO}_{2}$ seeps is about one in 100 million/year and that an engineered CCS storage site would be even safer, given the project planning and monitoring requirements. (This research was based on deaths from natural $\mathrm{CO}_{2}$ seepage in Italy as a result of volcanic activity.)

With respect to environmental impacts of $\mathrm{CO}_{2}$ leakage, Jones et al. (2015, p.353) found few published quantified data for leakage scenarios and suggested this is because of high uncertainty, especially in predicting deep geological flow; however their review also found no 'direct evidence of significant leakage from existing storage sites.' Bellarby (2012) suggested where geologic migration might not necessarily reach the 
biosphere, rates could be so low as to be undetectable and hence not of major concern. Koornneef et al. (2012) suggested failure of the underground $\mathrm{CO}_{2}$ storage system would have limited environmental consequences, thus suggesting a low risk; however, significant uncertainty in the assessment of this risk has the potential to become a bottleneck for wide scale implementation of CCS if not properly addressed. The findings from the elicitation appear to indicate that at a general level uncertainty for leakage and its negative effects remains high.

Leakage events remain a performance and containment hazard of serious concern in terms of public perception of the risks of CCS technology overall. As these events may occur as a consequence of well leakage, injection, intrinsic or induced storage hazards, acceptable leakage rates and impacts need to be determined (Stenhouse et al., 2009). On the other hand, the overarching purpose of CCS could be negated should substantial amounts of $\mathrm{CO}_{2}$ release back to the atmosphere. Expert elicitation target questions for risk management, as discussed in the companion article considered: long-term retention of $\mathrm{CO}_{2}$; a regulated threshold for likelihood of minor, major or catastrophic storage leakage; safe storage lifetimes; the proportion of environment and human health risk management and costs within CCS project operations (from both regulatory and liability points of view); effectiveness of risk management options for six low probability high impact events; and the storage monitoring period. Together, findings are of great value in planning the safe deployment of future CCS facilities.

\section{Conclusions}

Risk assessment and management has developed as a matter of judgement in probability and uncertainty since publication of the so-called 'Red Book', Risk Assessment in the Federal Government: Managing the Process (National Research Council, 1983). In the case of carbon capture and storage, projects have proceeded concurrently with an expanding knowledge base over the past 20 years. At a project level, Gerstenberger and Christophersen (2016), in their reporting of a CCS-related expert elicitation, reiterated the notion that all relevant uncertainties should be considered if practitioners are to obtain a robust and credible estimate of the risk.

The elicitation reported here did not consider a specific project site. Rather, its purpose was to contribute understanding of relative risk in CCS activities and to quantify, in a preliminary way, collective uncertainty judgements across experts for a number of environmental and human health issues that are expected to be discussed during future large scale sequestration project risk assessments. A companion paper in this volume describes complementary findings for risk management (Larkin et al., 2019a).

Analysis of the expert group's individual pairwise choices indicate persisting uncertainty, as manifest in low coefficients of agreement/concordance for risk ranking in technology, environment and health in each of capture, transport, injection and storage; relative long term risk of three storage options; and relative risk of several distinct causes of local health or environmental hazards in a low-moderate populated area. On the other hand, consistent views were provided for the pairwise preference matrix of relative reactivity of five naturally occurring minerals with $\mathrm{CO}_{2}$ in pure supercritical and dissolved state.

Based on the Classical Model of Cooke (Aspinall and Cooke, 2013; Colson and Cooke, 2018; Cooke, 1991), quantitative estimates of uncertainty in performance and 
containment risk issues indicate a wider credible range for equal weight $(\mathrm{EW})$ compared with performance weight (PW) in almost all questions. Among the findings, the PW credible range indicates a decreasing likelihood of minor, major, catastrophic leakage in capture, transport, injection and storage over three timeframes; wide uncertainty in worldwide saline aquifer storage capacity $(0.1-76,000 \mathrm{Gt})$; wide uncertainty in ultimate sequestration capacity of $\mathrm{CO}_{2}$ in solution, as a percent of a deep saline aquifer $(0.2-33 \%)$, increasing to $1 \%-76 \%$ with the use of horizontal well drilling strategy; and wide uncertainty in the modal distance potentially affected by salt precipitation $(1-175 \mathrm{~m})$. PW median judgements indicated that minor leakage is a virtual certainty in capture; the likelihood of minor, major and catastrophic storage leakage is almost equal but decreasing over three timeframes; the likelihood of leakage resulting in measurable effects on the environment or human health is essentially equal for three time periods $(0.1 \%)$; and that $28 \mathrm{Gt}$ worldwide storage capacity may be less than required for potential $\mathrm{CO}_{2}$ mitigation using saline sequestration, as envisioned by the IEA through 2050 (cumulative storage of up to $94 \mathrm{GtCO}_{2}$ ) (IEA, 2016).

These judgements may change as further information becomes available and for specific project proposals. The supplementary material provides examples of individual's responses that have a smaller range of uncertainty than the group as a whole, in some cases suggesting 'two schools of thought' within the expert panel. Examples include storage leakage likelihoods over three time periods and the global sequestration capacity in saline aquifers. In principle, these apparent dichotomies might be resolved by further, more detailed exploration of issues and contributory factors. On the other hand, Garthwaite et al. (2005) [cited in Gerstenberger et al. (2015, p.156)] suggested "extreme probability events are inherently very small numbers and thus are particularly difficult for experts to conceptualise and to give reasonable estimates thereof."

Some informational 'noise' of this nature may also be expected given the limited experience in CCS to date. Throughout the elicitation process, the expert panel was invited to offer comments on the questions and on the process itself. One panel member suggested that at this particular point in time, perhaps experts in $\mathrm{CO}_{2}$ storage do not yet exist. CCS is a new interdisciplinary technology, where experts' judgements in some cases appear to indicate no clear shared opinion (no definitive, reliable, exact number). Some panel members suggested additional important CCS topics that could be investigated in a focused elicitation include induced seismicity, thermo-hydro-chemicalmechanical coupled processes and the risks and benefits of CCS within broader climate change mitigation options.

\subsection{Observations on the elicitation process}

The classical model for structured expert elicitation is a well-established approach for gauging expert opinion in matters where there exists considerable uncertainty (Aspinall, 2008, 2010; Colson and Cooke, 2017, 2018; Cooke, 1991, 2009, 2013). Concerns about expert bias are reduced through an anonymised elicitation procedure with a formal, transparent and auditable processing of responses and a performance-based weighting scheme for pooling judgements. This encourages experts to be open minded in responding with their estimates and uncertainties, based on their own personal knowledge, expertise and experience.

Participating experts are internationally recognised authorities on technical risks in $\mathrm{CCS}$, with the central objective being safe and effective deployment that prevents health 
or environmental impacts in the short and long term. Resulting opinions are therefore useful points of reference for policy makers with respect to broad environmental and human health risk issues.

The choice of calibration questions and experts' knowledge with respect to these topics is a critical success factor for the elicitation. As with previous elicitations using this method, the goal is to provide calibration questions that reflect and fairly represent the specialist knowledge necessary for the expert elicitation target questions (Gerstenberger and Christophersen, 2016). In our case, given the complexity of CCS risk issues over lengthy periods of time, both the calibration and target questions may not have been within the purview of all the participants and, if they felt it appropriate, experts were permitted to decline to answer particular items.

Given that this exercise was not site dependent, the elicitation instrument and open discussion attempted to ensure the same understanding among experts of the problem context, definitions and question content; that is, that experts had the same picture in their mind as they responded individually to the elicitation instrument. Experts suggested that these understandings could have been repeated more often as the instrument was completed.

A re-elicitation attempted to address issues in understanding that became apparent from the Classical Model analysis. Nevertheless, unresolved ambiguity for some target questions could be reflected in the uncertainty distribution illustrated in the responses. While this elicitation was successful in linking international experts through video conferencing (thus also reducing the carbon footprint of the event), the re-elicitation was completed individually whereas a second plenary session might have assisted with further developing the common understanding for this series of questions. Gerstenberger et al. (2015) also found useful results and the possibility of obtaining better responses using an iterative process involving feedback and more than one expert meeting.

Nonetheless, we suggest our findings provide a valuable basis and opportunity, to reflect on the collective set of judgements when saline sequestration projects are developed and reviewed. The present results provide considerable insight into how experts view the potential technical, environmental and health risks associated with the four value chain components for carbon capture and storage (capture, transport, injection and storage). These judgements will be useful in planning future deployments of this technology at different sites around the world and in evaluating CCS as a viable technology for mitigating fossil energy and industrial point source $\mathrm{CO}_{2}$ emissions, facilities that are major contributors to climate change.

Supplementary materials are available online at Harvard Dataverse (https://dataverse.harvard.edu/).

\section{Acknowledgements}

The authors are most grateful to the experts who participated in the elicitation (the order here not reflected in the anonymised range graphs): Stefan Bachu, Michael Celia, Rick Chalaturnyk, Jean-Pierre Deflandre, William Gunter, Don Lawton, Curtis Oldenburg, Lincoln Paterson, David Ryan, J. Carlos Santamarina and Ton Wildenborg. The authors also thank three anonymous reviewers. This work was supported by DK, the Natural Sciences and Engineering Research Council of Canada Chair in Risk Science at the 
University of Ottawa. WPA was supported in part by the UK Natural Environment Research Council CREDIBLE consortium (Grant NE/J017299/1).

\section{References}

Aspinall, W. (2008) Expert Judgment Elicitation Using the Classical Model and EXCALIBUR, [online] http://dutiosc.twi.tudelft.nl/ risk/extrafiles/EJcourse/Sheets/Aspinall\%20Briefing\% 20Notes.pdf (accessed 30 August 2018).

Aspinall, W. (2010) 'A route to more tractable expert advice', Nature, 21 January, Vol. 463, pp.294-295.

Aspinall, W.P. and Cooke, R.M. (2013) 'Expert elicitation and judgement', in Rougier, J.C., Sparks, R.S.J. and Hill, L. (Eds.): Risk and Uncertainty Assessment in Natural Hazards, pp.64-99, Cambridge University Press, Cambridge, UK.

Bachu, S. (2003) 'Screening and ranking of sedimentary basins for sequestration of $\mathrm{CO}_{2}$ in geological media in response to climate change', Environmental Geology, Vol. 44, No. 3, pp.277-289, DOI: 10.1007/s00254-003-0762-9.

Bachu, S. (2015) 'Review of $\mathrm{CO}_{2}$ storage efficiency in deep saline aquifers', International Journal of Greenhouse Gas Control, Vol. 40, pp.188-202, DOI: 10.1016/j.ijggc.2015.01.007.

Bachu, S. and Watson, T.L. (2009) 'Review of failures for wells used for $\mathrm{CO}_{2}$ and acid gas injection in Alberta, Canada', Energy Procedia, Vol. 1, No. 1, pp.3531-3537, DOI: 10.1016/j.egypro.2009.02.146.

Bellarby, J. (2012) Annex A1 CO2 Storage Liabilities in the North Sea - An assessment of Risks and Financial Consequences, [online] https://www.gov.uk/government/uploads/system/ uploads/attachment_data/file/272211/Annex_A1_-_Well_Risks.pdf (accessed 30 August 2018).

Benson, S.M. (2007) Carbon Dioxide Capture and Storage: Research Pathways, Progress and Potential, [online] https://bensonlab.stanford.edu/sites/default/files/carbon_dioxide_capture_ and_storage_-_research_pathways_progress_and_potential.pdf (accessed 16 August 2018).

Benveniste, H., Boucher, O., Guivarch, C., Treut, H.L. and Criqui, P. (2018) 'Impacts of nationally determined contributions on 2030 global greenhouse gas emissions: uncertainty analysis and distribution of emissions', Environmental Research Letters, Vol. 13, No. 1, pp.014022, DOI: 10.1088/1748-9326/aaa0b9.

Birkholzer, J.T., Oldenburg, C.M. and Zhou, Q. (2015) ' $\mathrm{CO}_{2}$ migration and pressure evolution in deep saline aquifers', International Journal of Greenhouse Gas Control, Vol. 40, pp.203-220, DOI: $10.1016 /$ j.ijggc.2015.03.022.

Bowden, A.R., Pershke, D.F. and Chalaturnyk, R. (2013a) 'Biosphere risk assessment for $\mathrm{CO}_{2}$ storage projects', International Journal of Greenhouse Gas Control, Vol. 16, pp.S291-S308, DOI: $10.1016 /$ j.ijggc.2013.02.015.

Bowden, A.R., Pershke, D.F. and Chalaturnyk, R. (2013b) 'Geosphere risk assessment conducted for the IEAGHG Weyburn-Midale $\mathrm{CO}_{2}$ Monitoring and Storage Project', International Journal of Greenhouse Gas Control, Vol. 16, pp.S276-S290, DOI: 10.1016/j.ijggc.2013.02.014.

Celia, M.A., Bachu, S., Nordbotten, J.M. and Bandilla, K.W. (2015) 'Status of $\mathrm{CO}_{2}$ storage in deep saline aquifers with emphasis on modeling approaches and practical simulations', Water Resources Research, Vol. 51, pp.47, DOI: 10.1002/2015WR017609.

Colson, A.R. and Cooke, R.M. (2017) 'Cross validation for the classical model of structured expert judgment', Reliability Engineering \& System Safety, Vol. 163, pp.109-120, DOI: 10.1016/j.ress.2017.02.003.

Colson, A.R. and Cooke, R.M. (2018) 'Expert elicitation: using the classical model to validate experts' judgments', Review of Environmental Economics and Policy, Vol. 12, No. 1, pp.113-132, DOI: 10.1093/reep/rex022. 
Commission on Social Determinants of Health (2008) Closing the Gap in a Generation: Health Equity through Action on the Social Determinants of Health [online] http://www.who.int/social_determinants/thecommission/finalreport/en/ (accessed 30 August 2018).

Consoli, C.P. and Wildgust, N. (2017) 'Current status of global storage resources', Energy Procedia, Vol. 114, pp.4623-4628, DOI: 10.1016/j.egypro.2017.03.1866.

Cooke, R.M. (1991) Experts in Uncertainty: Opinion and Subjective Probability in Science, Oxford University Press, New York, NY.

Cooke, R.M. (2013) 'Validating expert judgment with the classical model', in Martini, C. and Boumans, M. (Eds.): Ethical Economy: Studies in Economic Ethics and Philosophy [online] http://www.expertsinuncertainty.net/LinkClick.aspx?fileticket=HlcTmEoDunY\%3D\&tabid=4 $385 \&$ mid $=8296$ (accessed 23 August 2018).

Cooke, R.M. (2009) 'Obtaining distributions from groups for decisions under uncertainty', in Williams, T., Samset, K. and Sunnevag, K. (Eds.): Making Decisions with Scant Information Front-End Decision Making in Major Projects, p.19, Palgrave MacMillan, Basingstoke, UK.

Cooke, R.M. and Goossens, L.L.H.J. (2008) 'TU Delft expert judgment database', Reliability Engineering and Systems Safety, Vol. 93, pp.657-674, DOI: 10.1016/j.ress.2007.03.005.

Dixon, T., McCoy, S.T. and Havercroft, I. (2015) 'Legal and regulatory developments on CCS', International Journal of Greenhouse Gas Control, Vol. 40, pp.431-448, DOI: 10.1016/j.ijggc.2015.05.024.

Duncan, I.J. and Wang, H. (2014) 'Estimating the likelihood of pipeline failure in $\mathrm{CO}_{2}$ transmission pipelines: new insights on risks of carbon capture and storage', International Journal of Greenhouse Gas Control, Vol. 21, No. 2014, pp.49-60.

GCCSI (2017) The Global Status of CCS: 2017 [online] https://www.globalccsinstitute.com/ projects/large-scale-ccs-projects (accessed 30 August 2018).

GCCSI (2018) Status of CCS Project Database [online] https://www.globalccsinstitute.com/ projects/large-scale-ccs-projects (accessed 20 September 2018).

Gerstenberger, M.C. and Christophersen, A. (2016) 'A Bayesian network and structured expert elicitation for Otway stage $2 \mathrm{C}$ : detection of injected $\mathrm{CO}_{2}$ in a saline aquifer', International Journal of Greenhouse Gas Control, Vol. 51, pp.317-329, DOI: 10.1016/j.ijggc.2016.05.011.

Gerstenberger, M.C., Christophersen, A., Buxton, R. and Nicol, A. (2015) 'Bi-directional risk assessment in carbon capture and storage with Bayesian networks', International Journal of Greenhouse Gas Control, Vol. 35, pp.150-159, DOI: 10.1016/j.ijggc.2015.01.010.

Hald, T., Aspinall, W., Devleesschauwer, B., Cooke, R., Corrigan, T., Havelaar, A.H., Gibb, H.J., Torgerson, P.R., Kirk, M.D., Angulo, F.J. and Lake, R.J. (2016) 'World Health Organization estimates of the relative contributions of food to the burden of disease due to selected foodborne hazards: a structured expert elicitation', PLOS ONE, Vol. 11, No. 1, p.e0145839, DOI: 10.1371 /journal.pone.0145839.

IEA (2013) Technology Roadmap Carbon Capture and Storage [online] https://www.iea.org/publications/freepublications/publication/TechnologyRoadmapCarbonCa ptureandStorage.pdf (accessed 16 August 2018).

IEA (2015) Carbon Capture and Storage: The Solution for Deep Emissions Reductions [online] https://www.iea.org/publications/freepublications/publication/carbon-capture-and-storagethesolution-for-deep-emissions-reductions.html (accessed 16 August 2018).

IEA (2016) 20 Years of Carbon Capture and Storage [online] https://www.iea.org/ publications/freepublications/publication/20YearsofCarbonCaptureandStorage_WEB.pdf (accessed 20 August 2018).

IPCC (2005) IPCC Special Report on Carbon Dioxide Capture and Storage [online] http://www.ipcc.ch/pdf/special-reports/srccs/srccs_wholereport.pdf (accessed 16 August 2018).

IPCC (2014) Summary for Policy Makers, Mitigation of Climate Change [online] http://www.ipcc.ch/report/ar5/wg3/ (accessed 16 August 2018). 
Jones, D.G., Beaubien, S.E., Blackford, J.C., Foekema, E.M., Lions, J., De Vittor, C., West, J.M., Widdicombe, S., Hauton, C. and Queirós, A.M. (2015) 'Developments since 2005 in understanding potential environmental impacts of $\mathrm{CO}_{2}$ leakage from geological storage', International Journal of Greenhouse Gas Control, Vol. 40, pp.350-377, DOI: 10.1016/j.ijggc.2015.05.032.

Ketzer, J.M.M., Machado, C.X., Rockett, G.C. and Iglesias, R.S. (2014) Brazilian Atlas of $\mathrm{CO}_{2}$ Capture and Geological Storage [online] http://hub.globalccsinstitute.com/sites/default/ files/publications/190903/brazilian-atlas-co2-capture-geological-storage.pdf (accessed 30 August 2018).

Koornneef, J., Ramirez, A., Turkenburg, W. and Faaij, A. (2012) 'The environmental impact and risk assessment of $\mathrm{CO}_{2}$ capture, transport and storage - an evaluation of the knowledge base', Progress in Energy and Combustion Science, Vol. 38, pp.62-86, DOI: 10.1016/j.pecs.2011.05.002.

Kunze, C. and Spliethoff, H. (2012) 'Assessment of oxy-fuel, pre- and post-combustion-based carbon capture for future IGCC plants', Applied Energy, June, Vol. 94, pp.109-116.

Larkin, P., Dusseault, M., Gracie, R.G., Sarkarfarshi, A.M., Shafiei, A., Aspinall, W. and Krewski, D. (2019a) 'Risk management in carbon capture and storage: insights from a structured expert elicitation', International Journal of Risk Assessment and Management, in this issue.

Larkin, P., Leiss, W. and Krewski, D. (2019b) 'The evolution of regulatory practice for CCS projects in Canada', International Journal of Risk Assessment and Management, in this issue.

Macutkiewicz, M. and Cooke, R.M. (2006) UNIBALANCE Users Manual [online] http://dutiosc.twi.tudelft.nl/ risk/images/stories/UnibalancePage/ Unibalance_User_Manual.pdf (accessed 4 August 2018).

MIT (2018) Carbon Capture \& Sequestration Project Database [online] http://sequestration.mit.edu/tools/projects/index.html (accessed 19 August 2018).

National Research Council (1983) Risk Assessment in the Federal Government: Managing the Process [online] www.nap.edu/catalog/366.html (accessed 16 August 2018).

North American Carbon Atlas Partnership (2012) North American Carbon Storage Atlas, First Edition [online] http://www.netl.doe.gov/File\%20Library/Research/Coal/carbon-storage/ global\%20collab/NACSA2012.pdf (accessed 30 August 2018).

Norwegian Petroleum Directorate (2013) ' $\mathrm{CO}_{2}$ storage atlas Norwegian sea', Directorate, N.P. Stavanger, NO: Norwegian Petroleum Directorate [online] http://www.npd.no/Global/Norsk/ 3-Publikasjoner/Rapporter/CO2-ATLAS-Norwegian-sea-2012.pdf (accessed 30 August 2018).

Oraby, T., Tyshenko, M., Westphal, M., Darshan, S., Croteau, M., Aspinall, W., Elsaadany, S., Cashman, N. and Krewski, D. (2016) 'Using expert judgments to improve chronic wasting disease management in Canada', Journal of Toxicology and Environmental Health, Vol. 79, No. 16-17, pp.713-28, DOI: 10.1080/15287394.2016.1174005.

Parkhurst, D.L. and Appelo, C.A.J. (2013) Description of Input and Examples for PHREEQC Version 3: A Computer Program for Speciation, Batch-Reaction, One-Dimensional Transport, and Inverse Geochemical Calculations [online] http://pubs.usgs.gov/tm/06/a43/pdf/tm6A43.pdf (accessed 15 August 2018).

Pawar, R.J., Bromhal, G.S., Carey, J.W., Foxall, W., Korre, A., Ringrose, P.S., Tucker, O., Watson, M.N. and White, J.A. (2015) 'Recent advances in risk assessment and risk management of geologic $\mathrm{CO}_{2}$ storage', International Journal of Greenhouse Gas Control, Vol. 40, pp.292-311, DOI: 10.1016/j.ijggc.2015.06.014.

Polson, D., Curtis, A. and Vivalda, C. (2012) 'The evolving perception of risk during reservoir evaluation projects for geological storage of $\mathrm{CO}_{2}$ ', International Journal of Greenhouse Gas Control, Vol. 9, pp.10-23, DOI: 10.1016/j.ijggc.2012.02.010.

Quintessa Ltd. (2018) $\mathrm{CO}_{2}$ FEP Database [online] https://www.quintessa.org/co2fepdb/v2.0.0/PHP/ frames.php (accessed 16 August 2018). 
Roberts, J.J., Wood, R.A. and Haszeldine, R.S. (2011) 'Assessing the health risks of natural $\mathrm{CO}_{2}$ seeps in Italy', Proceedings of the National Academy of Sciences of the United States of America, Vol. 108, No. 40, pp.16545-16548.

Sarkarfarshi, A., Ladubec, C., Gracie, R.G., Dusseault, M., Leiss, W. and Krewski, D. (2019) 'Potential technical hazards associated with four North American carbon capture and sequestration projects', International Journal of Risk Assessment and Management, in this issue.

Shell Canada Limited (2011a) 'Additional information on ERCB application no 1670112', available through Alberta Energy Regulator CD of documents related to the Quest application.

Shell Canada Limited (2011b) Quest Carbon Capture and Storage Project: Response to Supplemental Information Request \#2 [online] http://s00.static-shell.com/content/dam/shellnew/local/country/can/downloads/pdf/aboutshell/our-business/oil-sands/quest/sirs-responses2nov11.pdf (accessed 16 May 2018).

Siegel, J., Gilmore, E.A., Gallagher, N. and Fetter, S. (2018) 'An expert elicitation of the proliferation resistance of using small modular reactors (SMR) for the expansion of civilian nuclear systems', Risk Anal, Vol. 38, No. 2, pp.242-254, DOI: 10.1111/risa.12861.

Stenhouse, M.J., Gale, J. and Zhou, W. (2009) 'Current status of risk assessment and regulatory frameworks for geological $\mathrm{CO}_{2}$ storage’, Energy Procedia, Vol. 1, No. 1, pp.2455-2462, DOI: 10.1016/j.egypro.2009.02.007.

The Crown Estate and British Geological Survey (2016) $\mathrm{CO}_{2}$ Stored [online] http://www.co2stored.co.uk/home/index (accessed 4 August 2018).

Tyshenko, M., Elsaadany, S., Oraby, T., Darshan, S., Catford, A., Aspinall, W., Cooke, R. and Krewski, D. (2012) 'Expert judgement and re-elicitation for prion disease risk uncertainties', International Journal of Risk Assessment and Management, Vol. 16, No. 1/2/3, pp.48-77.

Tyshenko, M.G., ElSaadany, S., Oraby, T., Darshan, S., Aspinall, W., Cooke, R., Catford, A. and Krewski, D. (2011) 'Expert elicitation for the judgment of prion disease risk uncertainties', $J$ Toxicol Environ Health A, Vol. 74, No. 2-4, pp.261-85, DOI: $10.1080 / 15287394.2011 .529783$.

United Nations Framework Convention on Climate Change (2015) Adoption of the Paris Agreement, FCCC/CP/2015/L.9 [online] http://unfccc.int/resource/docs/2015/cop21/eng/ 109.pdf (accessed 16 August 2018).

United Nations Framework Convention on Climate Change (2016) Aggregate Effect of the Intended Nationally Determined Contributions: An Update [online] http://mitigationpartnership.net/ sites/default/files/aggregate_effect_of_the_intended_nationally_determined_contributions_an update.pdf (accessed 16 August 2018).

US Department of Energy (2015) Carbon Storage Atlas [online] http://www.netl.doe.gov/ File\%20Library/Research/Coal/carbon-storage/atlasv/ATLAS-V-2015.pdf (accessed 30 August 2018).

van der Meer, L.G.H. (1993) 'The conditions limiting $\mathrm{CO}_{2}$ storage in aquifers', Energy Conservation and Managememt, Vol. 34, No. 9-11, pp.959-966.

Watson, M. (2014) 'Containment risk assessment', in Cook, P. (Ed.): Geologically Storing Carbon: Learning from the Otway Project Experience, pp.129-140, CSIRO, Canberra, AU.

White, J.A. and Foxall, W. (2016) 'Assessing induced seismicity risk at $\mathrm{CO}_{2}$ storage projects: recent progress and remaining challenges', International Journal of Greenhouse Gas Control, Vol. 49, pp.413-424, DOI: 10.1016/j.ijggc.2016.03.021.

Wilson, E.J., Johnson, T.L. and Keith, D.W. (2003) 'Regulating the ultimate sink: managing the risks of geologic $\mathrm{CO}_{2}$ storage', Environmental Science and Technology, Vol. 37, No. 16, pp.3476-3483, DOI: $10.1021 / \mathrm{es} 021038$. 